INRA Prod. Anim.,

2014, 27 (3), 209-222

\title{
Intégrer la caractérisation du microbiote digestif dans le phénotypage de l'animal de rente : vers un nouvel outil de maîtrise de la santé en élevage?
}

\author{
F. CALENGE $E^{1,2}$, C. MARTIN ${ }^{3,4}$, N. LE FLOCH ${ }^{5,6}$, F. PHOCAS $S^{1,2}$, D. MORGAVI ${ }^{3,4}$, \\ C. ROGEL-GAILLARD ${ }^{1,2}$, P. QUÉRE $E^{7,8}$ \\ ${ }^{1}$ INRA, UMR1313 GABI, F-78352 Jouy-en-Josas \\ 2 AgroParisTech, UMR1313 GABI, 16 rue Claude Bernard, F-75321 Paris, France \\ ${ }^{3}$ INRA, UMR1213 Herbivores, F-63122 Saint-Genès-Champanelle, France \\ ${ }^{4}$ Université de Clermont-Ferrand, VetAgro Sup, UMR1213 Herbivores, F-63000, Clermont-Ferrand, France \\ 5 INRA, UMR1348 PEGASE, F-35590 Rennes, France \\ ${ }^{6}$ Agrocampus Ouest, UMR1348 PEGASE, F-35000 Rennes, France \\ 7 INRA, UMR1282 ISP, F-37380 Nouzilly, France \\ 8 Université François Rabelais, UMR1282 ISP, F-37200 Tours, France
}

Courriel :quere@tours.inra.fr

Les techniques de séquençage à haut débit ont considérablement accéléré nos connaissances sur le microbiote digestif. Au-delà de son rôle dans la digestion, le microbiote interagit avec l'animal hôte pour en réguler la physiologie et l'immunité, et plus globalement pour garantir l'adaptation de celui-ci à l'environnement. Utiliser la description du microbiote digestif pour évaluer la santé chez l'animal d'élevage n'est plus utopique. C'est même une nécessité pour la mise au point d'outils de diagnostic des dysfonctionnements du microbiote digestif et de moyens pour optimiser la santé en élevage via son contrôle.

Il est connu depuis longtemps que, chez l'Homme comme chez les animaux d'élevage, des microbiotes commensaux vivent aux interfaces entre l'organisme et le milieu extérieur (peau, muqueuses buccale, nasale, vaginale), comme aux interfaces entre certains organes et des milieux internes (tube digestif). Le microbiote du tube digestif, qui est quantitativement le plus important, surpassant en nombre de cellules celui de l'hôte qui l'héberge d'un facteur 10 et en nombre de gènes d'un facteur 100 , est parmi les plus étudiés.

La communauté microbienne du tube digestif est un écosystème complexe qui se compose de bactéries mais aussi, avec des proportions variables selon l'hôte considéré, d'archées, d'eucaryotes (protozoaires, champignons, levures) et de virus. Les bactéries sont réparties dans trois principaux phylums : Bacteroidetes, Firmicutes et Proteobactéries, dans des proportions variables selon l'espèce animale et le compartiment digestif considéré. Le terme de microbiote digestif désigne l'ensemble des microbes du tube digestif. Des travaux récents menés pour la plupart chez l'Homme ont mis en évidence de multiples interactions entre ce microbiote et son hôte, dont il est un constituant fonctionnel essentiel. Il a même été proposé de classer le microbiote digestif comme un nouvel organe chez l'Homme. De plus les études en biologie de l'évolution lui attribuent un rôle majeur dans l'adaptation à l'environnement. En particulier, il est impliqué dans l'adaptation des espèces aux changements d'alimentation du fait de ses rôles dans la nutrition et dans la limitation du développement des pathogènes, reposant sur la modulation de l'efficacité du système immunitaire et du métabolisme (Ottaviani et al 2011, Blottière et al 2013). Cette adaptation n'est possible que si cet écosystème varie dans sa composition et/ou son fonctionnement selon les conditions environnementales.

Les animaux doivent donc être considérés comme des « super-organismes » qui ont co-évolué avec leurs microbiotes commensaux et dont la biologie est déterminée par les gènes codés par leur génome propre en association avec les gènes des partenaires microbiens (Blaser et al 2013). Donc, le phénotype des animaux exprimé dans un environnement est autant dépendant de la régulation de l'expression de leurs gènes propres que de celle des gènes de leur microbiote. Le tableau 1 donne un aperçu de la variabilité de la composition taxonomique des espèces bactériennes du microbiote digestif dans certains compartiments du tube digestif selon l'espèce de rente considérée. De façon générale, l'estomac, le duodénum, le jéjunum sont relativement pauvres en bactéries comparativement à l'iléon et au gros intestin chez le porc et la poule. Le ruminant a par contre un compartiment pré-gastrique, le rumen, qui est particulièrement riche en nombre de bactéries et en diversité microbienne adaptée à la digestion des fourrages.

L'Organisation Mondiale de la Santé définit la santé comme suit: « la santé est un état complet de bien-être physique, mental et social, et ne consiste pas simplement en une absence de maladie ou d'infirmité ». Cette définition donnée pour l'Homme peut aussi valoir pour les animaux d'élevage, pour lesquels il 
Tableau 1. Composition des microbiotes digestifs de la vache, du poulet, du lapin et du porc.

\begin{tabular}{|lcccc|}
\hline & $\begin{array}{c}\text { Vache } \\
\text { rumen }\end{array}$ & $\begin{array}{c}\text { Poulet } \\
\text { caecum }\end{array}$ & $\begin{array}{c}\text { Lapin } \\
\text { caecum }\end{array}$ & $\begin{array}{c}\text { Porc } \\
\text { iléon }\end{array}$ \\
Bactéries (\%) & & & & \\
\hline Bacteroidetes & 51,0 & 1,9 & 3,1 & 13,5 \\
\hline Firmicutes & 41,6 & 70,0 & 92,5 & 67,5 \\
\hline Proteobacteria & 5,46 & 21,5 & 0,4 & 17,7 \\
Autres & 1,94 & 6,6 & 4,0 & 1,3 \\
\hline Archées & + & + & + & + \\
Protozoaires & + & nd & nd & nd \\
\hline Champignons & +- & nd & nd & nd \\
\hline Virus & + & + & + & + \\
\hline Levures & + & nd & +- & nd \\
\hline
\end{tabular}

Pour les bactéries, les proportions relatives des trois principaux phylums présents sont données à travers quatre exemples : rumen de la vache (Jami et Mizrahi 2012), caeca du poulet (Zhu et al 2002), caeca du lapin (Michelland et al 2012) et iléon du porc (Schmidt et al 2011). La concentration en bactéries est de l'ordre de $10^{9}$ à $10^{11}$ bactéries $/ \mathrm{mL}$ (rumen de la vache) ou /g (autres espèces). II est important de noter que ces proportions peuvent varier considérablement pour une même espèce et un même compartiment digestif en fonction des conditions d'élevage et de l'environnement. Si la composition en bactéries a été relativement bien étudiée pour chaque espèce, en revanche la présence d'autres organismes est souvent très peu étudiée. Ainsi, toutes les espèces sont susceptibles de porter des champignons, des protozoaires ou des levures, mais très peu d'études sont menées pour l'instant pour les quantifier et les caractériser. Lorsque les données manquent ou sont absentes, le tableau mentionne " nd " (non démontré).

convient donc de prendre en compte le bien-être. La gestion intégrée de la santé en élevage a pour objectif d'optimiser les rendements de production en préservant la santé et le bien-être des animaux, tout en contrôlant l'impact sur la santé publique en limitant l'utilisation des antibiotiques notamment, et en réduisant la dissémination des bactéries pathogènes. Dans ce contexte, du fait de ses rôles multiples dans la régulation de la physiologie de son hôte et de son rôle de barrière vis-à-vis des pathogènes, l'étude du microbiote digestif suscite donc un vif intérêt de la recherche en productions animales. En s'appuyant sur les nouveaux concepts élaborés à partir des dernières recherches chez l'Homme et des données disponibles sur les animaux domestiques quand elles existent, l'objet de cette revue est $i$ ) de faire ressortir les rôles essentiels et multiples du dialogue dynamique entre microbiote digestif et animal hôte pour le maintien d'un état de santé satisfaisant ; ii) de faire un point sur les avancées technologiques permettant de décrire les microbiotes digestifs et d'étudier leurs variations chez les animaux d'élevage; et iii) de s'interroger sur les mines (vitamine $\mathrm{K}, \mathrm{B} 12$ par exemple) qui ne sont pas synthétisées (ou peu) chez leur hôte ;

- trophique, en induisant le développement du tube digestif, du système immunitaire et du système nerveux et en régulant l'homéostasie par la modulation de la prolifération des cellules épithéliales digestive et l'ostéogénèse ;

- barrière, en limitant l'implantation de bactéries pathogènes directement par des mécanismes de résistance à la colonisation et indirectement en stimulant le système immunitaire (Buffie et Pamer 2013).

Les modèles gnotobiotiques animaux obtenus par suppression de la flore digestive ou implantation de flores contrôlées, constituent des outils remarquables pour analyser finement et valider ces rôles. La majorité des études ont été réalisées chez la souris (Yi et Li 2012). Mais il faut étoffer les données chez les animaux de rente. Le porc, modèle animal présentant un intérêt certain pour la physiologie humaine, est le deuxième modèle le plus étudié (Shirkey et al 2006, Willing et Van Kessel 2007). Les études publiées sont rares chez le ruminant (Fonty et al 1991) en dépit du grand intérêt suscité par le rumen. Pour évaluer l'universalité du rôle du microbiote digestif dans la physiologie, d'autres travaux sont en cours chez les oiseaux, le poulet en particulier (Projets européens EMIDA HEALTHYGUT 2011-2014 et DIFAGH 2013- 2015).

\section{1 / Le microbiote et le dévelop- pement du tube digestif}

La fonction première du tube digestif est la digestion. Son épithélium doit donc faciliter l'absorption des nutriments, mais il doit aussi pouvoir empêcher la translocation des bactéries, pathogènes ou non (Sommer et Backhed 2013). Ainsi, l'absence de flore microbienne dans des modèles gnotobiotiques animaux se traduit par un défaut de différentiation de la bordure en brosse de l'épithélium intestinal, une réduction de la régénération cellulaire s'accompagnant de la diminution de l'épaisseur des villosités, et une modification de la perméabilité épithéliale chez le porc (Willing et Van Kessel 2007, Willing et Van Kessel 2009) et chez les oiseaux (Bohorquez et al 2011). L'étude de la mise en place de la flore digestive chez le jeune ruminant (Taschuk et Griebel 2012) et le lapereau (Combes et al 2013) souligne ce même rôle trophique. L'implantation du microbiote à la naissance et la diversification de celui-ci lors de périodes critiques de transition alimentaire comme le sevrage (cas des mammifères) influencent donc de façon majeure le développement du tube digestif après la naissance. 
Figure 1. Le microbiote intestinal et ses rôles multiples chez son hôte (adaptée de Sommer et Backhed 2013).

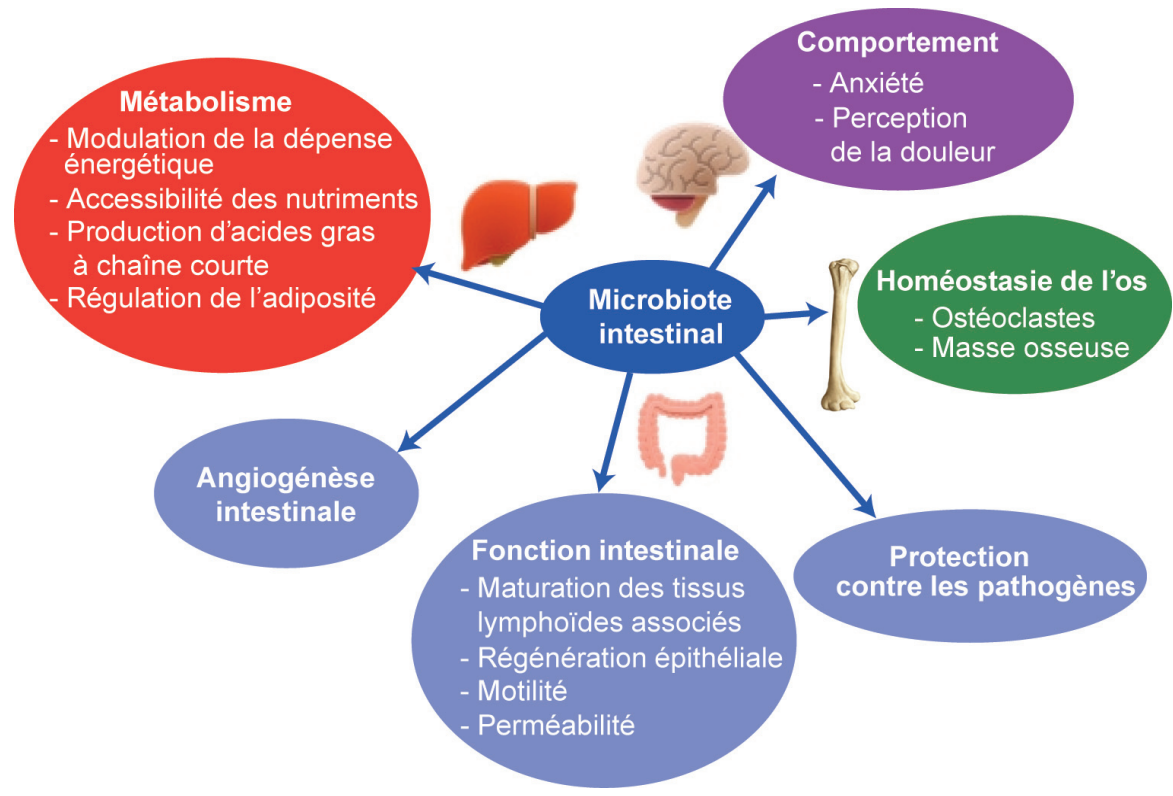

Le microbiote commensal prévient le développement des bactéries pathogènes dans le tube digestif. II agit sur la fonction de l'intestin en induisant la maturation du tissu lymphoide associé, l'intégrité de la barrière épithéliale, la motilité et la vascularisation. II interagit avec le métabolisme de l'hôte en permettant l'extraction de l'énergie des aliments et en favorisant l'adiposité. II influence le système nerveux en diminuant la connexion des synapses et en augmentant l'anxiété et la sensation de douleur. II influence l'homéostasie des tissus en favorisant par exemple la résorption osseuse.

\section{2 / Interactions avec le système immunitaire}

Pour maintenir l'homéostasie entre le microbiote commensal digestif, caractérisé par sa grande diversité, et l'hôte, le système immunitaire du tube digestif joue un rôle complexe (Hooper et al 2012, Sommer et Backhed 2013). Chez les animaux d'élevage, les études sont encore fragmentaires comparativement au modèle de choix murin, du fait de leur coût et du manque de disponibilité en outils d'analyse de la réponse immunitaire. Les mêmes mécanismes sembleraient globalement mis en jeu chez le porc (Chowdhury et al 2007, Inman et al 2010) et chez la poule (Brisbin et al 2008). Mais il est indispensable d'analyser de façon plus fine et exhaustive les spécificités propres à chaque espèce animale avant d'en tirer parti pour modifier les pratiques d'élevage. Un effort encore plus grand reste à prévoir pour les ruminants et les lagomorphes.

Dans le tube digestif, plusieurs mécanismes participent au maintien de l'équilibre bénéfique de la flore intestinale, équilibre dénommé eubiose (figure 2). La communauté des bactéries commensales dispose en propre de plusieurs mécanismes pour prévenir la colonisation par des bactéries pathogènes. Mais le système immunitaire du tube digestif joue aussi un rôle majeur pour éviter la multiplication excessive des bactéries commensales et le développement des bactéries pathogènes. De plus, il est le garant du maintien de l'intégrité de la barrière intestinale et inhibe la translocation de bactéries à travers l'épithélium. Les bactéries commensales sont associées soit aux particules alimentaires, soit au mucus produit par l'épithélium digestif. Dans ce mucus sont produites des molécules à effet antibactérien (peptides antimicrobiens comme les défensines et les lectines Reg III par exemple; les Immunoglobulines A ( $\operatorname{IgA})$ ). Le système immunitaire digestif compartimentalise ce microbiote par sa réponse au niveau local $i$ ) en limitant l'activation de la réponse contre des bactéries envahissantes au niveau des ganglions mésentériques chez les mammifères ; ii) en induisant une recirculation préférentielle locale des lymphocytes $\mathrm{T}$ et des lymphocytes B produisant les IgA et iii) en prévenant une activation délétère du système immunitaire systémique. Un déficit immunitaire comme par exemple l'absence d'IgA, se traduit par une modification profonde du microbiote avec en particulier l'expansion de bactéries segmentées filamenteuses dans l'intestrin grêle des souris (Suzuki et al 2007).

Réciproquement, le microbiote joue aussi un rôle clef dans le développement et le fonctionnement du système immunitaire du tube digestif (Hooper et al 2012,
Kamada et Nunez 2013, Sommer et Backhed 2013). Le microbiote modifie l'épaisseur et la composition du mucus. La réparation de l'épithélium digestif est stimulée après activation des voies de signalisation associées aux récepteurs innés détectant les composés bactériens. La génétique de l'hôte qui dicte le répertoire de ces récepteurs peut en ce sens moduler la fonction de la microflore intestinale commensale associée (Biswas et Kobayashi 2013, Rosenstiel 2013). La présence d'une flore microbienne permet d'induire le développement des structures lymphoïdes du tube digestif comme les plaques de Peyer iléales et jéjunales et les ganglions lymphatiques mésentériques, avec le développement des centres germinatifs qui sont les lieux de production et de différentiation des lymphocytes B, mais aussi des follicules lymphoïdes disséminés dans la muqueuse. La stratégie utilisée pour diversifier le répertoire des lymphocytes $B$ peut être très différente selon les espèces. Contrairement à l'Homme et à la souris, les espèces comme le mouton, la vache, le porc et le lapin, amplifient le nombre de lymphocytes B dans les tissus lymphoïdes associés à l'intestin après la naissance et diversifient leur répertoire par mutations somatiques, seulement s'il y a stimulation par le microbiote intestinal (Lanning et al 2005). Les rares données chez le poulet sont plus contradictoires quant à l'attribution d'un rôle majeur du microbiote dans la maturation du système immunitaire (Sayegh et Ratcliffe 2000). Certains genres de bactéries, comme les bactéries filamenteuses segmentées qui s'ancrent dans la muqueuse, stimulent la maturation des lymphocytes B (Imaoka et al 2004) et de certains lymphocytes $\mathrm{T}$ (Th17 à activité proinflammatoire) (Chung et al 2012). Il semblerait que cet effet soit spécifique de l'espèce bactérienne retrouvée chez l'hôte. Cette observation souligne donc la nécessité d'étudier les microbiotes associés à l'espèce d'intérêt pour préciser les relations hôte-système immunitaire car tout ne peut être transposé d'une espèce d'hôte à l'autre.

L'état d'eubiose (figure 2) s'accompagne de la mise en place d'un état de « tolérance immunitaire » caractérisé par la désactivation des macrophages, l'activation de lymphocytes T régulateurs (Treg) et la production de cytokines anti-inflammatoires (IL-10, TGF- $\beta$ ). Le microbiote exerce une activité modulatrice locale de la fonction des lymphocytes $\mathrm{T}$ dits invariants ( $\mathrm{Tbet}^{+}$ILCs) qui, sans contrôle, peuvent promouvoir l'inflammation, et des lymphocytes de type inné (ROR $\gamma \mathrm{t}^{+} \mathrm{ILCs}$ ), qui ont, eux, une action bénéfique protectrice de l'épithélium. Il est aussi maintenant prouvé que la modulation de la réponse mucosale 
Figure 2. Maintien d'un état d'eubiose (équilibre entre le microbiote commensal et son hôte) dans un intestin sain (adaptée de Brown et al 2013).

Eubiose

Communauté microbienne saine
Dysbiose

Déséquilibre

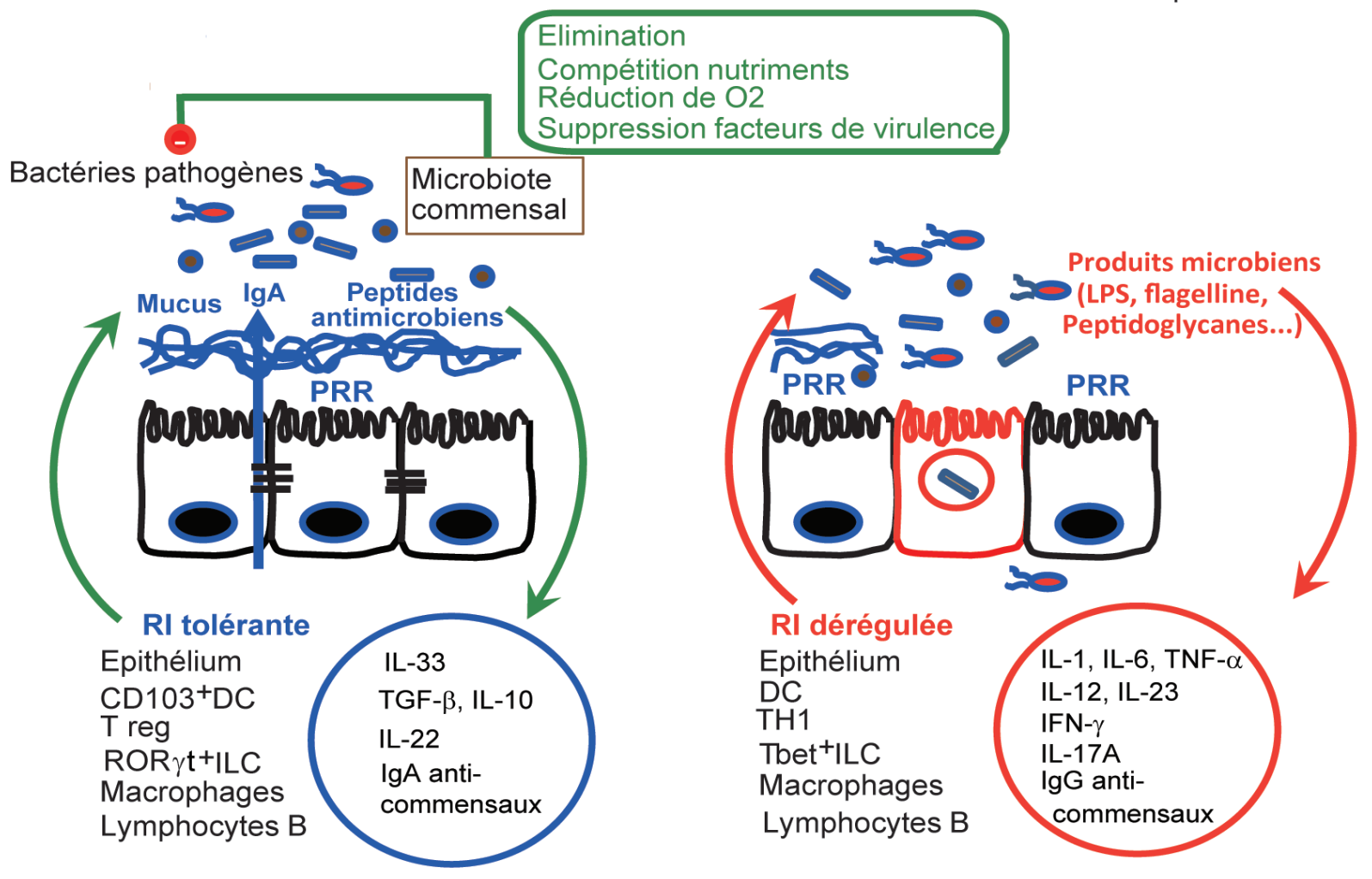

Les bactéries résidentes colonisent des niches intestinales et suppriment la multiplication des pathogènes par divers mécanismes (bactéricines, consommation de l'oxygène résiduel, production de métabolites...). Le microbiote commensal stimule aussi la fonction de barrière intestinale en induisant la production de mucus protecteur, la production de peptides antimicrobiens divers et en régulant la sécrétion d'IgA. Le dialogue microbiote commensal et système immunitaire de l'hôte met en place un état de tolérance immunitaire caractérisé par la production de cytokines immunosuppressives (IL-10, TGF- $\beta$ ), une désactivation des macrophages et l'activation d'un profil caractéristique de lymphocytes immunosuppresseurs (T régulateurs (Treg) ; Lymphocytes de type inné (ROR $\left.\gamma \mathrm{t}^{+} \mathrm{ILC}\right)$ ). Dans le cas de dysbiose, les bactéries pathogènes se multiplient et peuvent causer des dommages à l'épithélium intestinal. Les divers produits des parois bactériennes induisent une réponse pro-inflammatoire (IL-1, IL-6, TNF- $\alpha$, IFN- $\gamma$, IL-12, IL-17) avec un profil caractéristique de lymphocytes inflammatoires Th1 et innés (Tbet ${ }^{+}$ILC) et une réponse IgG. Les produits microbiens peuvent induire une inflammation systémique en passant dans le sang.

médiée par les lymphocytes $\mathrm{T}$ au travers de l'induction de sous-populations différentes ayant des effets pro- ou antiinflammatoires est contrôlée par différents phylums de bactéries commensales. L'interaction réciproque du système immunitaire digestif et du microbiote implique les cellules dendritiques intestinales, dont l'activation participe aux mécanismes d'induction de l'inflammation intestinale qui modifiera en retour le microbiote (Howarth et Wang 2013, Mann et al 2013). Dans le cas d'altération majeure de la composition de la flore digestive (dysbiose) et d'effraction de la barrière intestinale, les produits bactériens (endotoxines comme le LPS, peptidoglycanes, flagellines) activent le système immunitaire, déclenchant ainsi une inflammation délétère (figure 2). Chez l'Homme, des maladies inflammatoires de l'intestin comme la maladie de Crohn, la colite ulcérative et le syndrome de l'intestin irritable sont associées à des dysbioses (Aziz et al 2013).
De nouvelles données montrent aussi des effets du microbiote sur l'immunité générale, en particulier sur le profil de réponse immunitaire systémique $\mathrm{T}$, avec un pouvoir d'exacerbation de maladies inflammatoires systémiques ou de déclenchement de syndromes d'autoimmunité (Sonnenberg et al 2011, Hooper et al 2012).

\section{3 / Régulation du métabolisme}

D'après les nombreux travaux menés chez l'Homme, le microbiote digestif est impliqué dans l'homéostasie cellulaire et le métabolisme de différents tissus et organes de l'hôte (Holmes et al 2012). La figure 3 donne un aperçu du profil des métabolites produits à partir des nutriments par le microbiote dans le tube digestif, et qui agissent sur l'hôte soit directement, soit après transformation par le métabolisme de ce dernier. La fermentation des fibres alimentaires par la flore permet d'extraire l'énergie des ali- ments et de générer des acides gras à chaînes courtes comme le butyrate dont l'action trophique sur le tube digestif serait favorable à la santé, par exemple pour les porcelets au moment du sevrage (Le Gall et al 2009). Les acides gras volatils constituent une source d'énergie supplémentaire pour l'hôte, notamment dans le cas des ruminants $(\sim 75 \%$ des besoins d'entretien). Néanmoins diverses pathologies (par exemple l'obésité, le diabète de type II et l'athérosclérose chez l'Homme) sont considérées comme des syndromes de dysrégulation métabolique pour lesquels la composition du microbiote et sa régulation par le système immunitaire inné sont des déterminants critiques (Jin et al 2013). Dans le cas de l'obésité, par exemple, la pathologie peut être reproduite par le transfert de la flore digestive, ce qui en démontre le rôle comme facteur déclenchant et les possibilités de manipulations (Million et al 2013). Le microbiote peut affecter également le remodelage de l'os par 
Figure 3. Les axes métaboliques entre le microbiote intestinal et son hôte (adaptée de Holmes et al 2012).

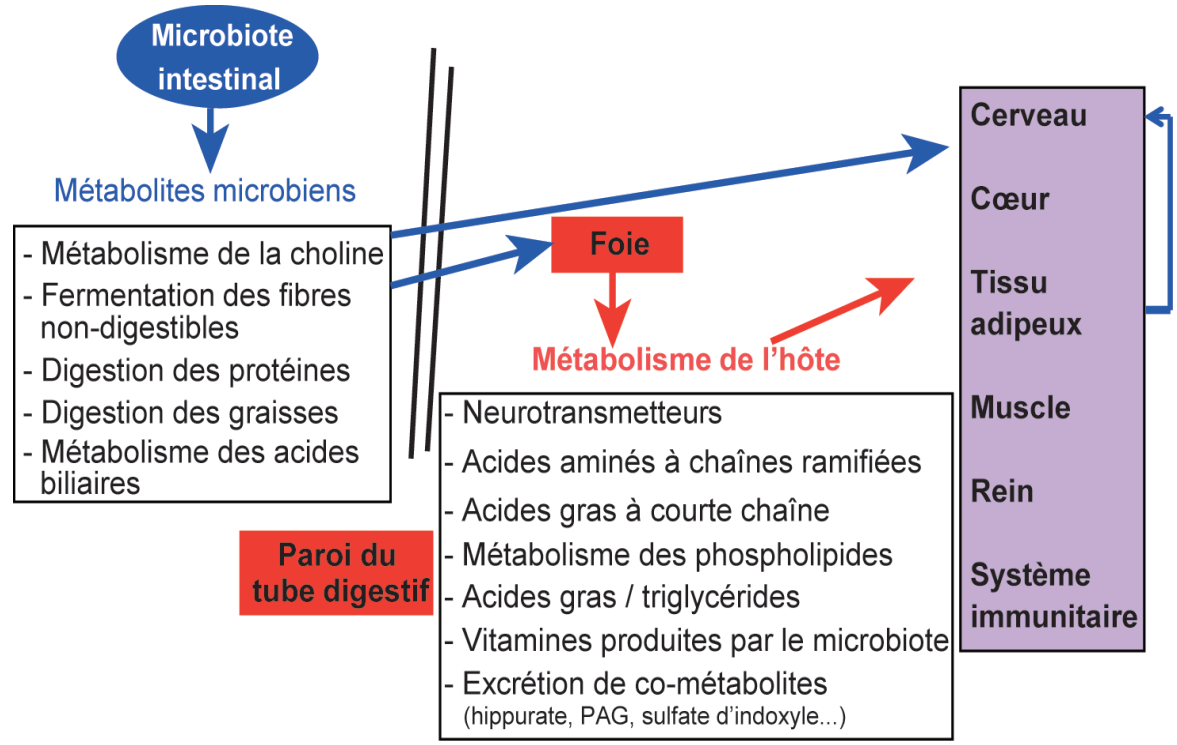

Le microbiote synthétise à partir des nutriments dans la lumière du tube digestif des métabolites qui sont absorbés à travers l'épithélium digestif et qui interagissent avec différents organes, soit directement, soit après avoir été métabolisés par le foie. Les axes métaboliques de la communication hôte-microbe incluent les neurotransmetteurs, les acides gras à chaîne courte (métabolisme de l'énergie), les acides aminés à chaîne ramifiée, les métabolites des phospholipides, les produits bactériens de la dégradation de la choline, les triglycérides et acides gras, les vitamines produites par les bactéries (vitamine K, vitamine B12 par exemple) et les co-métabolites des acides aromatiques et phénoliques. Tous ces axes influent sur la physiologie et la santé de l'hôte.

réduction de la masse osseuse en induisant un effet pro-inflammatoire et une activation des ostéoclastes (Sommer et Backhed 2013). Le rôle du microbiote sur les troubles locomoteurs des animaux de rente et son impact en élevage restent de fait à être évalués.

\section{4 / Communication avec le système nerveux}

Un nouveau concept est en émergence d'après les travaux menés chez l'Homme, celui d'un axe d'interactions bidirectionnelles entre le cerveau et le microbiote digestif, au point que ce dernier est parfois appelé « petit cerveau » (Collins et al 2012). L'existence de cet axe est prouvée chez la souris. Les dysbioses du microbiote digestif sont capables de modifier le niveau global d'anxiété et le comportement (Abouesh et al 2002, Salonen et al 2010, Bercik et al 2011). Cette découverte que des changements de comportement peuvent trouver leur origine dans des variations du microbiote digestif ouvre la porte à de nouvelles perspectives d'actions thérapeutiques (Bercik et al 2011). Cette communication microbiotecerveau emprunte des voies nerveuses, via le nerf vague ou indépendamment de ce dernier. Elle se fait également par des mécanismes endocrinologiques et immunologiques via les cytokines circulantes (Desbonnet et al 2008, Desbonnet et al 2010, Lotrich et al 2011). Finalement stress (Collins et Bercik 2009, Bailey et al 2011).

Chez les animaux d'élevage, l'existence d'une communication entre cerveau et microbiote digestif ouvrirait des perspectives en matière d'évaluation et de gestion du bien-être animal qui ne sont encore pas explorées en relation avec le système d'élevage. L'alimentation et/ou l'utilisation d'additifs (antibiotérapie ciblée, probiotiques) resterai(en)t un (ou des) levier(s) d'intervention le(s) plus pertinent(s) pour pouvoir modifier le microbiote dans des conditions prévisibles de stress (modification du mode d'élevage, transport, abattage).

\section{2 / Apport des techniques d'analyse à haut débit à la connaissance du microbiote digestif}

Au vu des données sur les rôles multiples du microbiote intestinal dans la physiologie de son hôte, caractériser celui-ci de la façon la plus complète possible devient nécessaire autant pour les animaux d'élevage que pour l'Homme. L'essor des techniques de biologie moléculaire, puis de séquençage à haut débit, a permis de caractériser la fraction non cultivable des bactéries, qui représente plus de $80 \%$ des bactéries du microbiote digestif (cf.encadré). Quelle que soit la méthode envisagée, la description du microbiote dans son ensemble est établie par la caractérisation de la diversité des microbes et des proportions respectives

Encadré. Les méthodes à haut débit disponibles pour décrire la composition du microbiote et ses fonctions.

Analyse de la diversité bactérienne (ADN)

Séquençage du gène de l'ARN ribosomal 16S

- Analyse par phylogénie

- Détermination des équilibres entre groupes bactériens (OTUs)

- Intérêt : applicable à toute espèce d'hôte sans pré-requis

Analyse de l'ensemble des gènes bactériens par métagénomique quantitative - Méthode : séquençage de fragments d'ADN

- Pré-requis : constitution d'un catalogue de gènes par espèce animale

- Détermination des équilibres entre groupes bactériens

Etude du microbiote fonctionnel

Méta transcriptomique (ARN)

- Méthode: séquençage des ARN

- Analyse de diversité basée sur les gènes actifs (exprimés)

- Détermination du répertoire de gènes exprimés

Méta protéomique (protéines)

- Méthode : spectrométrie de masse

- Identification de protéines (enzymes)

Méta métabolomique (métabolites)

- Méthode : spectroscopie haute résolution

- Identification des métabolites du dialogue microbien chez l'hôte 
des groupes phylogénétiques identifiés. Le défi actuel reste néanmoins la gestion du grand nombre de données générées et leur annotation.

\section{1 / Séquençage des ARN 16S et $18 \mathrm{~S}$ ribosomaux}

Pour caractériser un microbiote, une approche applicable à toute espèce hôte consiste à séquencer la partie variable du gène de l'ARN 16S ribosomal pour les procaryotes et du gène de l'ARN ribosomal $18 \mathrm{~S}$ pour les eucaryotes. C'est la méthode de référence la plus répandue pour la phylogénie des communautés microbiennes. Les séquences obtenues permettent d'identifier des unités taxonomiques opérationnelles (OTU) qui sont ensuite assignées aux microbes présents (classe, ordre, familles voire genres), sans affiner toutefois jusqu'à l'espèce ou la souche. C'est la méthode préférentiellement utilisée à l'heure actuelle chez l'animal.

\section{2 / Métagénomique quantitative}

La métagénomique quantitative est une méthode d'analyse sans a priori, à la différence de la précédente, qui vise à caractériser la diversité et la fréquence de l'ensemble des gènes du microbiote. Cette approche, si elle est plus lourde à mettre en œuvre, est aussi beaucoup plus fine et plus complète, car elle renseigne également sur les fonctions potentiellement présentes. Elle nécessite des développements propres à l'espèce hôte d'intérêt, avec comme pré-requis la constitution d'un catalogue de gènes de référence, établi grâce au séquençage de microbiotes provenant d'un nombre d'individus représentatifs de la variabilité de l'espèce considérée, suivi de l'annotation des gènes identifiés. L'approche de métagénomique quantitative est ainsi basée sur un séquençage complet à haut débit du microbiote à caractériser, suivi d'un alignement des séquences obtenues sur le catalogue de référence et d'une quantification de la fréquence des gènes. Le catalogue de gènes du microbiote intestinal a été caractérisé chez l'Homme dans le cadre du vaste projet européen MetaHit (Qin et al 2010). Des travaux sont engagés à l'INRA dans le cadre du méta-programme MEM, en collaboration avec le BGI («Beijing Genome Institute »), pour constituer le catalogue de gènes du microbiote intestinal du porc, et du microbiote du rumen de la vache. Il est probable que des catalogues de gènes des microbiotes intestinaux seront également constitués pour le lapin et la poule.

\section{3 / Métatranscriptomique}

La métatranscriptomique consiste à séquencer l'ensemble des gènes transcrits par un microbiote, attribuant ainsi un profil fonctionnel bactérien global, puis à établir la composition taxonomique des bactéries dites « actives ». La grande variabilité individuelle du microbiote intestinal établie par séquençage de l'ARN 16S suggère que des bactéries différentes peuvent accomplir la même fonction (Turnbaugh et al 2009). Selon certains, ce serait donc moins la composition du microbiote qu'il est important de considérer que ses fonctions (Backhed 2012). De fait une étude de méta-transcriptomique à partir de fèces d'individus en bonne santé chez l'Homme a prouvé une plus grande homogénéité de la composition taxonomique du microbiote actif que ne le suggérait l'hétérogénéité globale (Gosalbes et al 2011). La caractérisation du méta-transcriptome du microbiote intestinal est donc à envisager chez les animaux d'élevage pour avoir une meilleure idée des gènes actifs.

\section{4 / Métabolomique}

La composition et l'activité du microbiote digestif influent de façon majeure sur le profil métabolique de son hôte et donc sur son fonctionnement biologique. Comme nous l'avons vu (figure 3), les principaux métabolites impliqués dans la communication hôte-microbes proviennent de la conversion des nutriments dans la lumière intestinale et des produits du métabolisme de l'hôte. Ils sont transportés dans tout le corps. Evaluer ce profil chez l'hôte permettrait donc d'assigner des fonctionnalités métaboliques au microbiote intestinal. La démarche prospective actuelle en médecine humaine est de définir un profil métabolique des produits dérivés de l'activité du microbiote à partir de fluides biologiques ou des tissus par spectrométrie de masse et de le valider en miroir de la composition du microbiote. Cette démarche suppose une connaissance préalable précise des métabolites d'intérêt issus du microbiote. Elle n'a pas encore abouti à l'heure actuelle à des résultats concrets de diagnostic de dysbiose ou de mise au point de thérapie. Par analogie et au vu des progrès technologiques d'analyse à haut débit, il n'apparaît plus utopique de prévoir le même type de démarche pour relier le profil métabolique de l'hôte et les gènes exprimés par le microbiote pour mettre au point des outils utilisables aussi dans la maîtrise de l'élevage de précision selon l'espèce d'élevage considérée. Mais les données manquent encore dans ce domaine pour en évaluer la faisabilité. Une autre approche consiste à caractériser de façon systématique tous les métabolites produits par le microbiote digestif, à partir des contenus digestifs, ce qui donne une idée précise de l'activité du microbiote et de ses effets potentiels sur l'hôte (voir par exemple Lu et al 2014). L'intérêt de cette approche reste à être exploré chez les animaux d'élevage.

\section{5 / Conclusion sur les métho- des d'analyse à haut débit}

Le séquençage des gènes codant pour les ARN $16 \mathrm{~S}$ et $18 \mathrm{~S}$ est la méthode la plus facile et la moins coûteuse à l'heure actuelle. Cette méthode a de ce fait été beaucoup employée et demeure la méthode de référence. La métagénomique quantitative est cependant en plein développement et est incontournable pour une étude approfondie du microbiote digestif. Les méthodes de métatranscriptomique et de métamétabolomique sont complémentaires des autres approches dans le cadre d'une étude approfondie, mais leur apport pour une caractérisation de routine en élevage doit pour l'instant être discuté en fonction des avancées technologiques et scientifiques.

\section{3 / Comment relier variabi- lité du microbiote digestif et santé ?}

La notion de santé serait maintenant envisagée comme un état dynamique reposant sur les capacités d'adaptation aux variations des conditions de vie, qui pourrait découler en partie de la dynamique des communautés microbiennes du microbiote digestif (Hartman et al 2009, Morowitz et al 2011). Ainsi, la description du microbiote digestif pourra faire partie intégrante du phénotypage de la santé de l'hôte en tant que symbionte.

En médecine humaine, la majorité des études intégrant la description des microbiotes intestinaux se sont d'abord focalisées sur l'identification des spécificités de ceux-ci en relation avec des pathologies précises. Cette approche s'est avérée fructueuse pour certaines pathologies, en débouchant même sur la mise au point d'outils thérapeutiques (par exemple transfert de flore fécale). Cependant la définition d'une bonne santé ne saurait se réduire à l'absence de pathologie. La démarche est maintenant d'élargir l'attention aux microbiotes associés à une bonne santé et sur un grand nombre d'individus, pour en élucider les caractéristiques et propriétés en définissant ce que l'on pourrait appeler des profils de microbiotes bénéfiques (Backhed et al 2012, Blottière et al 2013). Certaines divergences du microbiote digestif chez un individu par rapport à ces profils de microbiotes bénéfiques pourraient être alors considérées comme des facteurs de risque de maladie. De plus ces recherches permettraient de s'intéresser à des perspectives d'intervention globale par l'utilisation du microbiote 
digestif et sa manipulation pour préserver un état de santé.

\section{1 / La variabilité individuelle du microbiote digestif}

\section{a) Résultats acquis chez l'Homme}

Les études récentes de métagénomique menées chez l'Homme ont démontré une grande variabilité individuelle de la composition des microbiotes, dont le microbiote digestif, à tel point que la composition du microbiote digestif serait spécifique à chaque individu. L'hypothèse défendue est que cette variabilité serait due à l'effet de sélection exercé par l'environnement au sens large sur les communautés bactériennes (Consortium HMP 2012). Mais il n'est pas possible de distinguer précisément, en étudiant des populations humaines distinctes mais qui partagent une origine et des habitudes alimentaires et culturelles communes, la part à attribuer aux facteurs génétiques de celle à attribuer aux facteurs externes. Une étude sur les grands singes démontre la part quasi exclusive des facteurs externes dans les différences entre la composition du microbiote dans des populations géographiquement séparées au sein d'une même région (Moeller et Ochman 2013). En dépit de cette grande variabilité, un « noyau » commun de communautés bactériennes partagé par plusieurs individus sains, dont on peut présumer qu'il est indispensable au fonctionnement du microbiome digestif, est mis en évidence (Arumugam et al 2011). Toutefois, il est vrai que ce noyau ne suffit pas, à lui seul, à remplir toutes les fonctions attribuées au microbiote. Du fait de l'existence d'une grande redondance fonctionnelle d'un groupe bactérien à l'autre, la composition du microbiote peut donc différer d'un individu à l'autre tout en assurant les mêmes fonctions.

De plus, un microbiote étant un écosystème, sa composition n'est pas le seul paramètre à considérer pour le décrire : les équilibres entre groupes bactériens, sa diversité, sa dynamique de colonisation, sa stabilité dans le temps, et sa capacité de résilience et de retour " à la normale " après une agression (Sansonetti 2011) peuvent également être étudiés. On sait par exemple que chez un adulte sain, le microbiote digestif, quelle que soit sa composition, revient à une composition stable proche de l'état initial après avoir été perturbé par un traitement antibiotique (résilience) (Dethlefsen et Relman 2011). Par ailleurs, bien que la diversité individuelle de composition du microbiote digestif humain soit grande, il semble que les microbes hébergés par le tractus gastrointestinal humain tendent à adopter une communauté de structure particulière, baptisée entérotype. Il existerait trois grands entérotypes facilement identifiables par les équilibres entre trois genres bactériens : Bacteroides, Prevotella et Ruminococcus (Qin et al 2010, Arumugam et al 2011). Plus intéressant encore, trois entérotypes sont également présents chez les grands singes. Ils sont stables avec le temps, mais il peut y avoir un changement d'un entérotype à l'autre au cours de la vie de l'individu (Moeller et al 2012). Il reste particulièrement pertinent de déterminer, chez l'Homme, si des entérotypes différents entrainent des réponses différentes aux mêmes pathologies.

L'idée prévaut aussi que le maintien d'une grande diversité chez l'individu des genres bactériens pourrait être associé à une meilleure santé. Chez l'Homme, la standardisation des modes de vie et des habitudes alimentaires avec des régimes trop riches en sucres, graisses et en calories peut provoquer un appauvrissement de la biodiversité des microbiotes digestifs, qui s'allie à de nouvelles pathologies et à des désordres immunologiques (De Filippo et al 2010, Clemente et al 2012). Il a été démontré que des individus obèses possédant un microbiote digestif de faible richesse en gènes, donc a priori de faible diversité, montraient un niveau d'inflammation à bas bruit et des dysfonctionnements métaboliques (Cotillard et al 2013).

\section{b) Application aux animaux d'élevage}

Chez les animaux d'élevage, les études de la diversité de composition du microbiote par séquençage restent rares, en particulier pour les monogastriques, si bien qu'on manque encore d'informations pour savoir si la variabilité individuelle du microbiote intestinal est analogue à celle de l'Homme. Une étude a tout de même montré, dans le rumen, la présence d'un microbiote noyau partagé par plusieurs individus nourris avec le même régime alimentaire en dépit d'une grande variabilité globale entre individus (Jami et Mizrahi 2012).

Il apparait important d'étudier les descripteurs de l'écosystème digestif, notamment diversité, résilience et équilibres entre groupes bactériens, dans des conditions variables (alimentation, conditions climatiques, type d'élevage). Ce type d'étude est un pré-requis indispensable avant d'étudier l'impact du microbiote sur la santé. Il conviendrait de hiérarchiser les facteurs de variation du microbiote digestif : existe-t-il par exemple des entérotypes reconnaissables quel que soit le type d'élevage ou le génotype de 1'hôte ? La génétique de l'hôte a-t-elle un rôle important ? De fait la définition de profils bénéfiques de microbiotes chez des animaux élevés dans des environnements maîtrisés fixés par la génétique, l'alimentation et les conditions d'élevage serait souhaitable. Le lapin pourrait être un bon exemple d'application (Combes et al 2013). Une étude chez le porc a également montré que le type d'élevage durant les premières semaines de vie a une influence sur la composition du microbiote intestinal. Ainsi, des porcs élevés en plein air présentent une prédominance de Firmicutes, en particulier du genre lactobacillus, comparativement aux porcs confinés dans un milieu sanitairement propre qui, eux, ont une proportion plus forte de phylotypes potentiellement pathogènes. Ces différences sont exagérées en isolateurs. En corollaire, l'immunité innée du tube digestif est activée dans les environnements à hygiène maîtrisée et donc l'homéostasie immunitaire est modifiée. Il semble donc souhaitable dans ce cas de favoriser la colonisation du tube digestif porcin par des lactobacilles (Mulder et al 2009, 2011).

\section{2 / Variabilité selon les com- partiments digestifs : faut-il la prendre en compte?}

La composition du microbiote digestif n'est pas identique tout au long du tube digestif, tant dans le sens longitudinal du transit que dans le sens axial (de la muqueuse vers la lumière intestinale). Chaque section a un rôle spécifique au cours de la digestion. Chez les animaux d'élevage, les compartiments digestifs les plus étudiés sont ceux pour lesquels la richesse bactérienne est la plus grande et l'impact de la composition de l'aliment le plus fort : rumen de la vache (de Menezes et al 2011, Fouts et al 2012, Jami et Mizrahi 2012, Morgavi et al 2013), caecum du lapin (Monteils et al 2008, Michelland et al 2011), iléon et caecum du poulet (Torok et al 2008, Yeoman et al 2012) et gros intestin du porc (Schmidt et al 2011, Isaacson et Kim 2012). Dans le cas particulier des poissons, outre le tube digestif (Wong et Rawls 2012), le mucus de la peau contient aussi un microbiote variable selon les différents environnements et qu'il conviendrait plutôt d'étudier car plus facile à cibler (Austin 2006). De fait la peau des poissons est associée à un système immunitaire muqueux semblable à celui de l'intestin (Xu et al 2013).

En raison de cette variabilité le long du tube digestif, l'étude du microbiote digestif nécessiterait donc en théorie de collecter pour chaque animal plusieurs échantillons par section du tube digestif. C'est évidemment très difficile à envisager dans une optique de phénotypage de grands groupes d'animaux. De plus, des prélèvements non invasifs sont à 
privilégier pour des raisons de facilité et d'acceptabilité, tout en gardant la possibilité de réaliser plusieurs prélèvements au cours de la carrière d'un même animal. Par conséquent, étudier la flore des fèces s'avère être une alternative à privilégier malgré de nombreuses limites. En effet, il est admis que, si le prélèvement de fèces donne une représentation partielle du microbiote intestinal, il n'en est pas le reflet strict, comme cela a été montré chez l'Homme et la souris (Segata et al 2012, Eloe-Fadrosh et Rasko 2013). Chez le poulet, les phylums principaux retrouvés dans les fèces proviennent du gros intestin (Sekelja et al 2012). Des différences de composition sont aussi observées entre le rumen et les fèces (Michelland et al 2009, Callaway et al 2010). Enfin chez le lapin, les deux types de fèces (crottes dures et caecotrophes) ont des microbiotes de compositions différentes (Michelland et al 2012). En dépit du fait que les fèces ne reflètent qu'imparfaitement la totalité des microbiotes du tube digestif, leur étude demeure scientifiquement pertinente si les variations de leur composition peuvent être reliées à des variations phénotypiques d'intérêt chez l'animal. Néanmoins, pour les études génériques qui exigent de relier de façon précise des profils microbiens à la physiologie et la santé, il convient de considérer les différents compartiments digestifs qui ont une fonction digestive différente et ce, sur un échantillon d'animaux. C'est l'avantage de pouvoir travailler sur des prélèvements invasifs chez l'animal, ce qui est impossible chez l'Homme.

\section{3 / Variabilité selon l'âge physio- logique : conséquences sur la santé}

Les mammifères naissent avec un tube digestif stérile, qui est progressivement colonisé par le microbiote commensal après la naissance. La succession écologique des espèces microbiennes qui colonisent le tube digestif au cours de la vie se fait selon des fenêtres d'implantation spécifiques, avec un accroissement de la complexité au cours du temps. Ceci a été le plus étudié chez les mammifères comme le lapin (Combes et al 2013), mais a été aussi montré chez le poulet (Crhanova et al 2011). Le microbiote présent à la naissance est différent de celui trouvé à l'âge adulte, et il est aussi plus instable. Il est fourni par la mère et par l'environnement immédiat de l'animal. Chez les mammifères, il contribue à la digestion du lait maternel (Clemente et al 2012). Chez l'Homme, il est démontré que le mode d'accouchement (voie naturelle ou césarienne), le mode d'alimentation (lait maternel ou reconstitué) et la prise d'antibiotiques ont une influence sur la composition du microbiote intestinal qui s'implante à la naissance. Chez les mam- mifères, le sevrage est une période critique en élevage, pendant laquelle le microbiote digestif évolue, se diversifie et se stabilise pour assurer la transition à l'alimentation solide comme cela a été montré chez le porc (Rist et al 2012, Pluske 2013), le lapin (Combes et al 2011) et les ruminants (Oikonomou et al 2013). D'autres périodes de transition comme la parturition et le début de la lactation chez les mammifères (Martin et al 2006) peuvent se traduire par des perturbations du microbiote dues à des changements des apports alimentaires en qualité et/ou quantité.

Ces phases de transition pour la diversification du microbiote digestif doivent faire l'objet d'études approfondies chez les animaux d'élevage, car elles constituent potentiellement des moments privilégiés pour modifier le microbiote dans un sens favorable, et sont éventuellement des périodes de fragilité pour l'animal qui pourraient être anticipées ou traitées par la mise en place d'un microbiote favorisant la robustesse.

\section{4 / La notion de « bonne santé » de l'hôte définie en regard du microbiote digestif}

Pour faire de la connaissance approfondie du microbiote digestif un outil de gestion de la santé en élevage, il ne suffit pas de le décrire. Il faut également analyser les conséquences de la variabilité observée du microbiote sur la santé de son hôte, ce qui nécessite de définir au préalable un profil de critères de « bonne santé » dans la population d'élevage considérée, se rapportant aux différentes fonctions biologiques d'intérêt. $\mathrm{Si}$ on définit la bonne santé en terme de robustesse, c'est-à-dire de résistance, d'adaptation et de résilience face aux agressions de l'environnement (agents pathogènes, stress) tout en maintenant un niveau de production souhaité, alors ces critères pourraient décrire prioritairement l'expression du potentiel de production, la qualité de l'immunité au sens général (réponse aux infections, absence d'inflammation aiguë ou chronique) et le bien-être (sensibilité aux stress d'élevage, comportement social), qui correspondent aux axes privilégiés de dialogues réciproques entre l'hôte et son microbiote. A l'analyse clinique de l'état de santé des animaux devra s'ajouter en priorité l'immunophénotypage, à savoir i) la détermination de la formule sanguine ; ii) l'analyse des populations et souspopulations leucocytaires (cytométrie en flux) et iii) la quantification des protéines de l'inflammation et des cytokines circulantes (par des ELISA spécifiques, par dosage multiplexe ou par analyse transcriptomique des cellules sanguines...). Diverses technologies à haut débit doivent être développées en ce sens pour les animaux de rente et suffisamment d'études doivent être menées à cet effet pour définir les profils métaboliques, immunologiques et physiologiques de référence par espèce dans un contexte sain à mettre en relation avec un profil de microbiote sain (Phocas et al 2014, ce numéro). Le défi reste donc encore à l'heure actuelle de définir des « normes » en utilisant des critères objectifs de bonne santé, fiables et de mesure facile sur un grand nombre d'échantillons, qui ne sont pas encore tous disponibles pour la plupart des espèces d'élevage.

\section{4 / Questions de recherche identifiées}

L'accumulation des données sur la description du microbiote digestif et de ses particularités pour chaque espèce animale de rente avec les nouvelles méthodes de séquençage et d'analyse à haut débit, permettra de mieux en connaître les facteurs de variation et de comprendre les interactions fines avec l'hôte. Ce travail n'en est qu'à ses débuts pour la majorité des espèces de rente. Au-delà du nécessaire travail préliminaire de description des variations du microbiote digestif en fonction de ces facteurs pour chaque espèce animale, de nombreuses questions de recherche doivent être abordées en vue de la prise en compte du microbiote digestif pour améliorer la robustesse des animaux, dans le contexte d'un élevage de précision.

\section{1 / Définir la meilleure méthode d'échantillonnage du microbiote digestif dans une approche de gestion de la santé en élevage}

Pour certains animaux d'élevage, l'échantillonnage de plusieurs portions du tube digestif sur plusieurs individus devient envisageable pour des études approfondies des rôles du microbiote, dans la mesure où les techniques de séquençage se démocratiseront. Pour les études à grande échelle sur le terrain, les fèces sont le type de prélèvement non invasif le plus facile à considérer, sauf pour certaines comme les oiseaux et les poissons. Cependant la description de leur microbiote apportera des informations imparfaites qui risquent d'être difficiles à interpréter car, comme nous l'avons souligné précédemment, la composition du microbiote des fèces n'est pas le reflet de celle de tous les compartiments du tube digestif. Donc, il reste encore à rechercher s'il est quand même possible d'identifier à partir de la composition du microbiote des fèces les altérations spécifiques d'intérêt de chaque compartiment digestif pour chaque espèce d'élevage. 


\section{2 / Définir des outils de dia- gnostic et de prédiction de dys- biose intestinale en élevage}

Comme indiqué dans la figure 4 , la mise en relation des critères de bonne santé avec des paramètres descriptifs du microbiote digestif d'animaux sains ou montrant une dysbiose intestinale devrait permettre d'identifier des paramètres du microbiote associés avec des marqueurs de dysfonctionnement pathologique chez l'hôte. Ces paramètres pourraient devenir des marqueurs de dysbiose utilisables pour diagnostiquer, voire prédire, la survenue de dysbioses digestives en élevage et les conséquences sur la santé de l'animal. Ils pourraient devenir un outil précieux, car les dysbioses sont parfois difficiles à diagnostiquer à l'heure actuelle.

\section{3 / Identifier les facteurs condui- sant à une dysbiose intestinale en élevage}

Maîtriser les facteurs déclenchant une dysbiose digestive est essentiel en élevage, mais il n'est pas toujours facile de les identifier précisément. Les infections par des pathogènes (bactéries, mais aussi virus ou parasites) sont les causes les plus connues d'agression de la muqueuse digestive qui peuvent conduire à des états d'inflammation locale et/ou systémique. Ces modifications initiales peuvent se pérenniser et se traduire en retour par des modifications plus ou moins durables de la flore digestive même après la disparition de la cause. Il apparait donc trop simpliste de persister à considérer qu'un seul microbe est responsable de la maladie digestive (Clemente et al 2012). Il est important d'explorer dans le futur la complexité des interactions entre un ou plusieurs pathogènes (bactéries, virus, parasites) et le microbiote digestif dans la survenue, l'exacerbation et la persistance des dysbioses digestives. Des exemples sont donnés dans le cas d'entérites à point de départ bactérien, à savoir l'entérite nécrotique de la poule (Shojadoost et al 2012), ou à point de départ parasitaire chez les ruminants (Li et al 2011) et le porc (Li et al 2012). Les traitements médicamenteux comme l'antibiothérapie et l'ingestion de toxines (pesticides, mycotoxines) conduisent aussi à des modifications de la flore digestive. Il est vraisemblable que les particularités individuelles du microbiote digestif de chaque animal engendrent des réponses différentes face à ces facteurs d'altération divers qui peuvent s'additionner en élevage.

L'étiologie d'autres syndromes qui sont en relation avec des dysbioses intestinales et qui sont observés particulièrement lors de périodes critiques d'élevage est plus difficile à analyser. Il

Figure 4. Mise au point d'outils pour la biologie prédictive et l'élevage de précision.

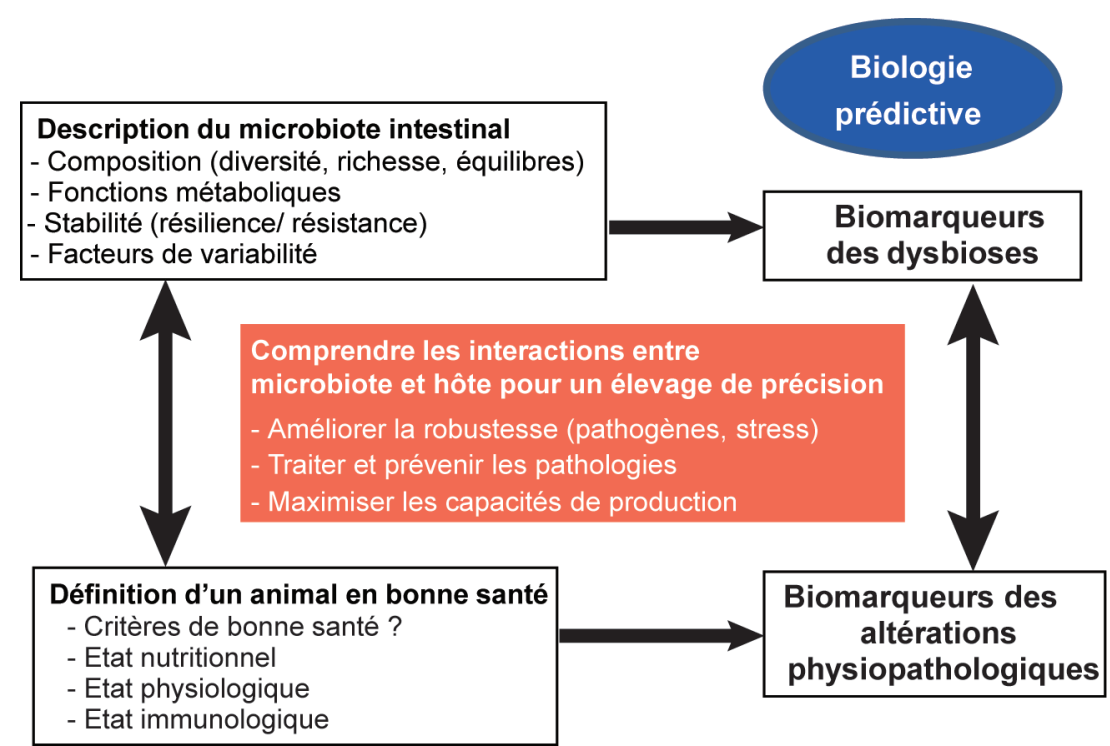

La découverte de biomarqueurs permettant d'identifier les dysbioses du microbiote intestinal en relation avec les altérations physiopathologiques de l'animal permettront ensuite d'ajuster le traitement des pathologies ou mieux de les prévenir afin de maximiser au final les capacités de production en adaptant l'alimentation, en stimulant l'immunité et en diminuant les causes de stress une fois identifiées.

s'agit du sevrage, de l'entrée en lactation ou en ponte, des changements de conduite ou de conditions environnementales d'élevage. Les diarrhées du sevrage dues à une sensibilité accrue aux pathogènes (porcelet, lapereau, veau) et l'acidose sub-clinique de la vache laitière (Khafipour et al 2009) sont des exemples majeurs de maladies multifactorielles dont il serait intéressant de comprendre de façon fine les mécanismes pour pouvoir en prédire la survenue avant l'expression de la phase clinique par l'identification de marqueurs de dysbiose, et donc pour pouvoir les prévenir.

\section{4 / Identifier des moyens d'inter- vention sur le microbiote digestif utilisables en élevage}

La figure 5 résume les facteurs majeurs qui influent sur la composition du microbiote digestif et sur lesquels on pourrait jouer pour maintenir un état d'eubiose ou guérir une dysbiose.

L'antibiothérapie ou à l'avenir la thérapie par l'administration de phages (encore en développement) sont les moyens qui permettent de modifier de façon ciblée la composition du microbiote digestif en éliminant les bactéries pathogènes si elles ont été identifiées. L'administration d'une flore fécale est aussi appliquée en médecine humaine dans des traitements de dysbioses digestives reflétant un déséquilibre plus large (Vrieze et al 2013). Cette approche constitue une piste de traitement même chez les animaux d'élevage, par exemple pour les dysbioses du sevrage comme chez le lapin. Pour cela, la connaissance précise des fenêtres de permissivité à la modification du microbiote digestif est nécessaire.

Mais du fait de la nécessité de supprimer l'utilisation des antibiotiques comme facteurs de croissance pour éviter le développement de bactéries antibiorésistantes, la plus grande partie des recherches actuelles porte sur les probiotiques. Un probiotique se définit comme une préparation d'organismes vivants qui confèrent un bénéfice pour la santé de l'hôte après administration orale en quantité adéquate. L'utilisation des probiotiques est considérée comme appropriée chez le poulet pour faciliter l'adaptation à la période suivant l'éclosion et aux pratiques d'élevage (changements alimentaires, transport, manipulations, forte densité d'élevage) tout comme chez le porc et le lapin soumis à des facteurs environnementaux de stress induisant facilement un déséquilibre de l'écosystème intestinal (méthodes d'élevage, alimentation, sevrage), et enfin chez le ruminant (période avant le sevrage, réduction du portage des bactéries pathogènes chez l'adulte (Gaggia et al 2010, Huyghebaert et al 2011, Combes et al 2013).

L'alimentation reste le facteur majeur de modification globale et durable de la composition du microbiote digestif et de son métabolisme (Aitken et Gewirtz 2013, Jeffery et O'Toole 2013). En effet, elle est à même de favoriser la prévalence de certains phylums de bactéries par rapport à d'autres en induisant des conditions physicochimiques intestinales spécifiques et en mettant à disposition 
Figure 5. Facteurs de l'environnement et inhérents à l'hôte influençant la composition du microbiote digestif (adaptée de Maslowski et Mackay 2011).

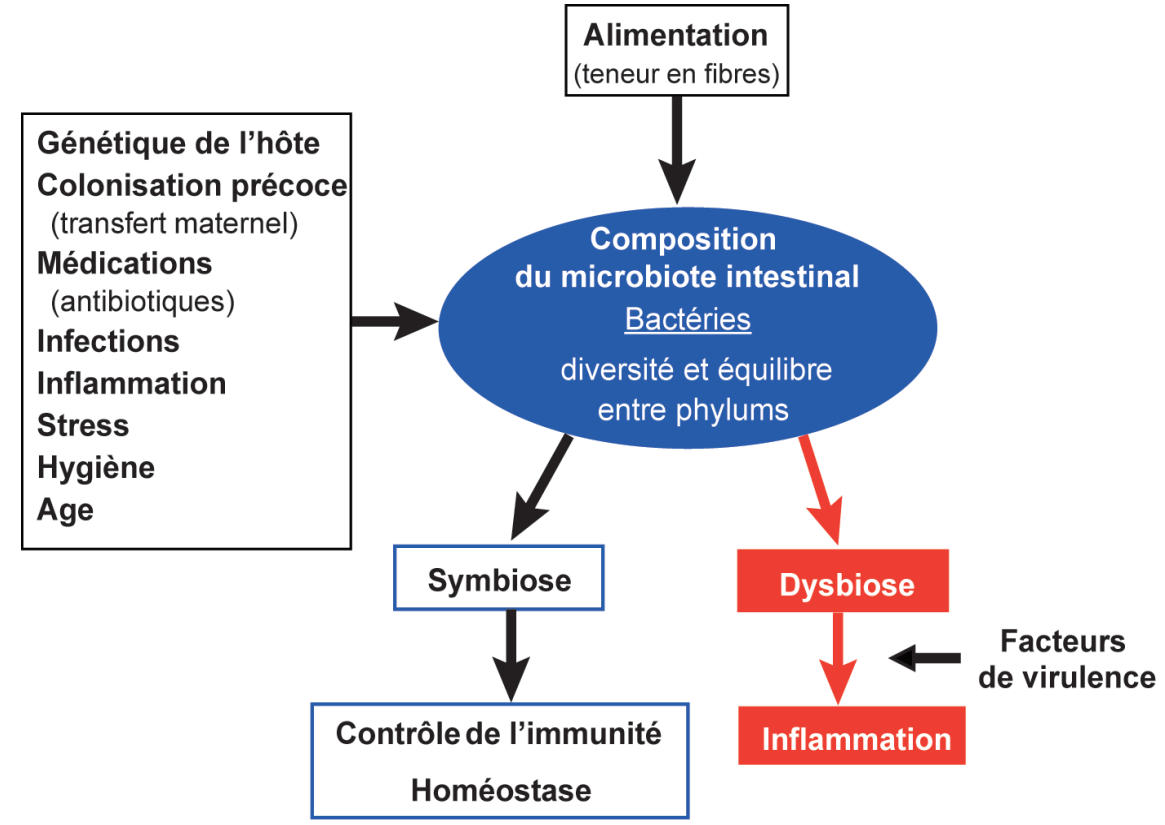

La flore qui s'implante à la naissance (transfert maternel) est un déterminant de la composition du microbiote de l'individu qui évoluera ensuite au cours de sa vie. Cette composition se modifie avec l'âge et pourrait être contrôlée en partie par la génétique de l'hôte (à prouver). Elle est conditionnée par des facteurs environnementaux (alimentation en particulier teneur en fibre, hygiène, mode de vie) et peut varier suite à l'exposition à des infections, des traitements antibiotiques et des stress. divers nutriments pour la croissance bactérienne. La teneur en fibres (et le type de fibres), la teneur en énergie ou en protéines ont un impact majeur. Chez l'Homme, par exemple, le type de régime influe très rapidement et de façon reproductible sur la composition du microbiote intestinal (David et al 2014). Une meilleure maîtrise de l'alimentation sera l'outil de choix dans l'élevage de précision pour permettre au mieux l'expression des génotypes, corriger les dysbioses métaboliques et aider à la résolution des problèmes infectieux. L'utilisation des prébiotiques est une piste d'appoint explorée en élevage, mais les effets sont parfois variables. Un prébiotique est un ingrédient nutritionnel non digestible qui bénéficie à son hôte en stimulant sélectivement la croissance et/ou l'activité d'un nombre limité de bactéries (Gaggia et al 2010, Huyghebaert et al 2011 ; Combes et al. 2013). Dans le cas particulier de l'acidose de la vache laitière, la formulation du régime alimentaire est cruciale pour réduire l'inflammation systémique et accroître la santé métabolique (Zebeli et Metzler-Zebeli 2012).

La génétique de l'animal hôte pourrait aussi être un moyen à considérer pour modifier le microbiote intestinal. Quelques études montrent chez l'Homme

Figure 6. Leviers d'intervention agissant sur la qualité du microbiote digestif pour améliorer la robustesse au cours des premières semaines de vie.

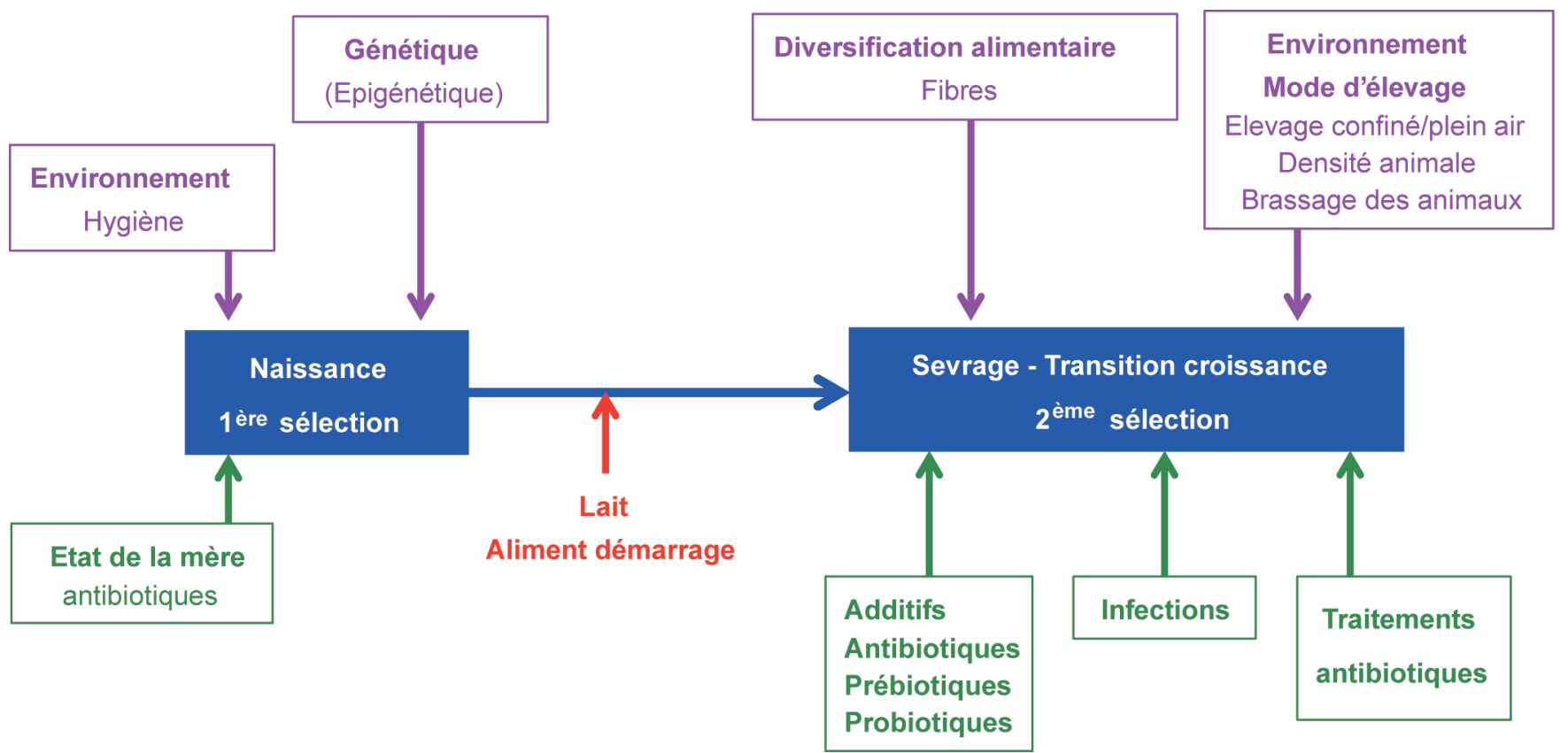

La qualité du microbiote intestinal transmis à la naissance (1 1 ère sélection) dépend de celui de la mère, de l'environnement d'élevage (hygiène) et de la génétique. Le microbiote intestinal est adapté à la digestion du lait puis l'alimentation se diversifie au sevrage pour les mammifères ( $2^{\text {ème }}$ sélection). Le sevrage est une période très critique de fragilité où l'utilisation d'additifs alimentaires (antibiotiques sélectifs, prébiotiques favorisant le développement de certains phylums de bactéries bénéfiques et probiotiques apportant des bactéries bénéfiques) prévient l'installation de pathologies digestives. La qualité de l'alimentation (teneur en fibres), l'environnement et le mode d'élevage sont les facteurs sur lesquels on peut jouer pour favoriser la mise en place d'un microbiote adulte sain favorable à la production. Les volailles ont une période critique de démarrage après la naissance et la diversification du microbiote semble jouer un rôle favorable pour améliorer l'immunité, la résistance aux infections et la croissance. 
(Khachatryan et al 2008) et la souris (Campbell et al 2012) que la composition de la flore est en partie sous contrôle génétique (cf. revue de Spor et al 2011)). Cette piste mérite d'être explorée chez les animaux d'élevage, dont on peut sélectionner les génotypes. En outre, des facteurs génétiques responsables de variations du microbiote intestinal pourraient constituer de précieux outils de prédiction.

La figure 6 donne, comme exemple, l'éventail des possibilités d'intervention sur le microbiote intestinal pour améliorer la robustesse des animaux d'élevage dans la période de fragilité après la naissance (mammifères, volaille).

\section{Conclusion}

Les rôles majeurs du microbiote digestif sur la physiologie de son hôte et sur son adaptation à l'environnement (génétique de l'hôte, type d'élevage, alimentation et maintenant variations climatiques) justifient son étude chez les espèces animales d'élevage. Les premiers résultats obtenus chez certaines espèces d'élevage sont très prometteurs. Mais intégrer la description du microbiote digestif comme une donnée à part entière du phénotype de l'individu pour mieux contrôler sa santé reste un défi (Blottière et al 2013). Des outils extrêmement performants d'analyse à haut débit (métagénomique, métatranscriptomique, protéomique, métabolomique) existent, mais leur utilisation nécessite au préalable de standardiser les méthodes d'analyse et d'échantillonnage, de perfectionner l'exploitation des données (statistiques) et de créer des outils de gestion de la santé en élevage.

Il convient d'abord d'acquérir de nombreuses données sur les variabilités inter- et intra-individuelle et sur les propriétés de cet écosystème complexe pour chaque espèce d'élevage étudiée selon les facteurs fixes de variation tels que la position au sein du tube digestif, l'âge physiologique et le génotype de l'hôte. La deuxième étape est d'intégrer les paramètres descripteurs du microbiote digestif (notamment la composition, la diversité et la capacité de résilience) dans une évaluation globale de la santé de l'hôte décrite en termes d'immunité, d'absence de maladies et de bienêtre évaluant l'adaptation aux conditions d'élevage (production). C'est ainsi que pourront être mis au point des outils de diagnostic de dysbioses digestives et des pathologies associées, des traitements reposant sur la modification directe du microbiote ou des moyens indirects pour favoriser un équilibre qui associe santé et production. Enfin, dans la mesure où le microbiote digestif influence non seulement la santé, mais aussi la digestion et le métabolisme de l'hôte, voire son comportement, il est nécessaire de mener des études intégrées des effets des variations de ce microbiote sur l'ensemble de ces caractères et pas uniquement sur la santé.
Finalement, la connaissance du microbiote digestif et de ses effets sur la physiologie normale de l'animal d'élevage et dans le cas de dysbiose devrait permettre le développement d'outils de contrôle de la santé dans l'élevage de précision du futur permettant :

- d'optimiser les critères de production en fonction des paramètres fixes d'élevage (notamment le génotype et l'âge physiologique) par le biais de l'alimentation ;

- d'augmenter la robustesse dès le jeune âge en favorisant l'installation d'un microbiote associé à une bonne santé et à une meilleure productivité ;

- d'augmenter la robustesse face à des environnements changeants (variations qualitatives des aliments, variations climatiques) ;

- de limiter l'utilisation d'antibiotiques pour préserver l'environnement et la stabilité du microbiote à l'âge adulte, en les substituant par l'usage de prébiotiques ou de probiotiques et une meilleure gestion de l'alimentation;

- d'identifier et d'anticiper les moments de fragilité des animaux et les facteurs d'altération du microbiote digestif selon le type de production considéré ;

- de maîtriser la sécurité sanitaire en évitant le développement de bactéries pathogènes pour l'Homme (salmonelles chez le porc et chez le poulet par exemple) et en réduisant les intrants médicamenteux dans la prophylaxie des pathologies digestives.

\section{Références}

Abouesh A., Stone C., Hobbs W.R., 2002. Antimicrobial-induced mania (antibiomania): a review of spontaneous reports. J. Clin. Psychopharmacol., 22, 71-81.

Aitken J.D., Gewirtz A.T., 2013. Gut microbiota in 2012: Toward understanding and manipulating the gut microbiota. Nat. Rev. Gastroenterol. Hepatol., 10, 72-74.

Arumugam M., Raes J., Pelletier E., Le Paslier D., Yamada T., Mende D.R., Fernandes G.R. Tap J., Bruls T., Batto J.M., Bertalan M., Borruel N., Casellas F., Fernandez L., Gautier L., Hansen T., Hattori M., Hayashi T. Kleerebezem M., Kurokawa K., Leclerc M., Levenez F., Manichanh C., Nielsen H.B., Nielsen T., Pons N., Poulain J., Qin J., Sicheritz-Ponten T., Tims S., Torrents D., Ugarte E., Zoetendal E.G., Wang J., Guarner F., Pedersen O., de Vos W.M., Brunak S., Doré J., Antolin M., Artiguenave F., Blottière H.M., Almeida M., Brechot C., Cara C., Chervaux C., Cultrone A., Delorme C., Denariaz G., Dervyn R., Foerstner K.U., Friss C., van de Guchte M., Guedon E., Haimet F., Huber W., van Hylckama-Vlieg J., Jamet A., Juste C., Kaci G., Knol J., Lakhdari O., Layec S., Le Roux K., Maguin E., Merieux A., Melo Minardi R., M'Rini C., Muller J., Oozeer R., Parkhill J., Renault P., Rescigno M., Sanchez N.,
Sunagawa S., Torrejon A., Turner K., Vandemeulebrouck G., Varela E., Winogradsky Y., Zeller G., Weissenbach J., Ehrlich S.D., Bork P., 2011. Enterotypes of the human gut microbiome. Nature, 473, 174-180.

Austin B., 2006. The bacterial microflora of fish, revised. Scient. World J., 6, 931-945.

Aziz Q., Doré J., Emmanuel A., Guarner F., Quigley E.M., 2013. Gut microbiota and gastrointestinal health: current concepts and future directions. Neurogastroenterol. Motility, 25, 4-15.

Backhed F., 2012. Host responses to the human microbiome. Nutr. Rev., 70, Suppl 1, S14-17.

Backhed F., Fraser C.M., Ringel Y., Sanders M.E., Sartor R.B., Sherman P.M., Versalovic J., Young V., Finlay B.B., 2012. Defining a healthy human gut microbiome: current concepts, future directions, and clinical applications. Cell Host Microbe, 12, 611-622.

Bailey M.T., Dowd S.E., Galley J.D., Hufnagle A.R., Allen R.G., Lyte M., 2011. Exposure to a social stressor alters the structure of the intestinal microbiota: implications for stressorinduced immunomodulation. Brain Behav. Immun., 25, 397-407.
Bercik P., Denou E., Collins J., Jackson W., Lu J., Jury J., Deng Y., Blennerhassett P., Macri J., McCoy K.D., Verdu E.F., Collins S.M., 2011. The intestinal microbiota affect central levels of brain-derived neurotropic factor and behavior in mice. Gastroenterol., 141, 599-609.

Biswas A., Kobayashi K.S., 2013. Regulation of intestinal microbiota by the NLR protein family. Int. Immunol., 25, 207-214.

Blaser M., Bork P., Fraser C., Knight R., Wang J., 2013. The microbiome explored: recent insights and future challenges. Nat. Rev. Microbiol., 11, 213-217.

Blottière H.M., de Vos W.M., Ehrlich S.D., Doré J., 2013. Human intestinal metagenomics: state of the art and future. Curr. Opin. Microbiol., 16, 232-239.

Bohorquez D.V., Bohorquez N.E., Ferket P.R., 2011. Ultrastructural development of the small intestinal mucosa in the embryo and turkey poult: A light and electron microscopy study. Poult. Sci., 90, 842-855.

Brisbin J.T., Gong J., Sharif S., 2008 Interactions between commensal bacteria and the gut-associated immune system of the chicken. Anim. Health Res. Rev., 9, 101-110. 
Brown E.M., Sadarangani M., Finlay B.B., 2013. The role of the immune system in governing host-microbe interactions in the intestine. Nat. Immunol., 14, 660-667.

Buffie C.G., Pamer E.G., 2013. Microbiotamediated colonization resistance against intestinal pathogens. Nat. Rev. Immunol., 13, 790801.

Callaway T.R., Dowd S.E., Edrington T.S., Anderson R.C., Krueger N., Bauer N., Kononoff P.J., Nisbet D.J., 2010. Evaluation of bacterial diversity in the rumen and feces of cattle fed different levels of dried distillers grains plus solubles using bacterial tag-encoded FLX amplicon pyrosequencing. J. Anim. Sci., 88, 3977-3983.

Campbell J.H., Foster C.M., Vishnivetskaya T., Campbell A.G., Yang Z.K., Wymore A., Palumbo A.V., Chesler E.J., Podar M., 2012. Host genetic and environmental effects on mouse intestinal microbiota. ISME J., 6, 20332044.

Chowdhury S.R., King D.E., Willing B.P., Band M.R., Beever J.E., Lane A.B., Loor J.J., Marini J.C., Rund L.A., Schook L.B., Van Kessel A.G., Gaskins H.R., 2007. Transcriptome profiling of the small intestinal epithelium in germfree versus conventional piglets. BMC Genomics, 8, 215.

Chung H., Pamp S.J., Hill J.A., Surana N.K., Edelman S.M., Troy E.B., Reading N.C., Villablanca E.J., Wang S., Mora J.R., Umesaki Y., Mathis D., Benoist C., Relman D.A., Kasper D.L., 2012. Gut immune maturation depends on colonization with a host-specific microbiota. Cell, 149, 1578-1593.

Clemente J.C., Ursell L.K., Parfrey L.W., Knight R., 2012. The impact of the gut microbiota on human health: an integrative view. Cell, 148, 1258-1270.

Collins S.M., Bercik P., 2009. The relationship between intestinal microbiota and the central nervous system in normal gastrointestinal function and disease. Gastroenterol., 136, 2003-2014.

Collins S.M., Surette M., Bercik P., 2012. The interplay between the intestinal microbiota and the brain. Nat. Rev. Microbiol., 10, 735-742.

Combes S., Michelland R.J., Monteils V., Cauquil L., Soulie V., Tran N.U., Gidenne T., Fortun-Lamothe L., 2011. Postnatal development of the rabbit caecal microbiota composition and activity. FEMS Microbiol. Ecol., 77, 680689.

Combes S., Fortun-Lamothe L., Cauquil L., Gidenne T., 2013. Engineering the rabbit digestive ecosystem to improve digestive health and efficacy. Animal, 7, 1429-1439.

Consortium HMP, 2012. Structure, function and diversity of the healthy human microbiome. Nature, 486, 207-214.

Cotillard A., Kennedy S.P., Kong L.C., Prifti E., Pons N., Le Chatelier E., Almeida M., Quinquis B., Levenez F., Galleron N., Gougis S., Rizkalla S., Batto J.M., Renault P., Doré J., Zucker J.D., Clement K., Ehrlich S.D., 2013. Dietary intervention impact on gut microbial gene richness. Nature, 500, 585-588.

Crhanova M., Hradecka H., Faldynova M., Matulova M., Havlickova H., Sisak F., Rychlik I., 2011. Immune response of chicken gut to natural colonization by gut microflora and to Salmonella enterica serovar enteritidis infection. Infect. Immun., 79, 2755-2763.
David L.A., Maurice C.F., Carmody R.N., Gootenberg D.B., Button J.E., Wolfe B.E., Ling A.V., Devlin A.S., Varma Y., Fischbach M.A., Biddinger S.B., Dutton R.J., Turnbaugh P.J., 2014. Diet rapidly and reproducibly alters the human gut microbiome. Nature, 505, 559563

De Filippo G., Rendina D., Strazzullo P., 2010 Childhood obesity, other cardiovascular risk factors, and premature death. N. Engl. J. Med., $362,1841-1842$.

de Menezes A.B., Lewis E., O’Donovan M. O'Neill B.F., Clipson N., Doyle E.M., 2011 Microbiome analysis of dairy cows fed pasture or total mixed ration diets. FEMS Microbiol Ecol., 78, 256-265.

Desbonnet L., Garrett L., Clarke G. Bienenstock J., Dinan T.G., 2008. The probiotic Bifidobacteria infantis: An assessment of potential antidepressant properties in the rat. J. Psychiatr. Res., 43, 164-174.

Desbonnet L., Garrett L., Clarke G., Kiely B., Cryan J.F., Dinan T.G., 2010. Effects of the probiotic Bifidobacterium infantis in the maternal separation model of depression. Neuroscience, 170, 1179-1188.

Dethlefsen L., Relman D.A., 2011. Incomplete recovery and individualized responses of the human distal gut microbiota to repeated antibiotic perturbation. Proc. Natl. Acad. Sci. U.S.A., 108, Suppl 1, 4554-4561.

Eloe-Fadrosh E.A., Rasko D.A., 2013. The human microbiome: from symbiosis to pathogenesis. Annu. Rev. Med., 64, 145-163.

Fonty G., Jouany J.P., Chavarot M., Bonnemoy F., Gouet P., 1991. Development of the rumen digestive functions in lambs placed in a sterile isolator a few days after birth. Reprod. Nutr. Dev., 31, 521-528.

Fouts D.E., Szpakowski S., Purushe J., Torralba M., Waterman R.C., MacNeil M.D., Alexander L.J., Nelson K.E., 2012. Next generation sequencing to define prokaryotic and fungal diversity in the bovine rumen. PLoS One, 7, e48289.

Gaggia F., Mattarelli P., Biavati B., 2010 Probiotics and prebiotics in animal feeding for safe food production. Int. J. Food Microbiol., 141, Suppl 1, S15-28.

Gosalbes M.J., Durban A., Pignatelli M. Abellan J.J., Jimenez-Hernandez N., Perez-Cobas A.E., Latorre A., Moya A., 2011. Metatranscriptomic approach to analyze the functiona human gut microbiota. PLoS One, 6, e17447.

Hanstock T.L., Mallet P.E., Clayton E.H., 2010. Increased plasma d-lactic acid associated with impaired memory in rats. Physiol. Behav., $101,653-659$

Hartman A.L., Lough D.M., Barupal D.K., Fiehn O., Fishbein T., Zasloff M., Eisen J.A. 2009. Human gut microbiome adopts an alternative state following small bowel transplantation. Proc. Natl. Acad. Sci. U.S.A., 106, 17187 17192.

Holmes E., Li J.V., Marchesi J.R., Nicholson J.K., 2012. Gut microbiota composition and activity in relation to host metabolic phenotype and disease risk. Cell Metab., 16, 559-564.

Hooper L.V., Littman D.R., Macpherson A.J. 2012. Interactions between the microbiota and the immune system. Science, 336, 1268-1273.

Howarth G.S., Wang H., 2013. Role of endogenous microbiota, probiotics and their biological products in human health. Nutrients, 5, 58-81.
Huyghebaert G., Ducatelle R., Van Immerseel F., 2011. An update on alternatives to antimicrobial growth promoters for broilers. Vet. J., 187, 182-188.

Imaoka A., Setoyama H., Takagi A., Matsumoto S., Umesaki Y., 2004. Improvement of human faecal flora-associated mouse model for evaluation of the functional foods. J. Appl. Microbiol., 96, 656-663.

Inman C.F., Haverson K., Konstantinov S.R., Jones P.H., Harris C., Smidt H., Miller B., Bailey M., Stokes C., 2010. Rearing environment affects development of the immune system in neonates. Clin. Exp. Immunol., 160, 431439.

Isaacson R., Kim H.B., 2012. The intestinal microbiome of the pig. Anim. Health Res. Rev., 13, 100-109.

Jami E., Mizrahi I., 2012. Composition and similarity of bovine rumen microbiota across individual animals. PLoS One, 7, e33306.

Jeffery I.B., O'Toole P.W., 2013. Diet-microbiota interactions and their implications for healthy living. Nutrients, 5, 234-252.

Jin C., Henao-Mejia J., Flavell R.A., 2013. Innate immune receptors: key regulators of metabolic disease progression. Cell. Metab., $17,873-882$.

Kamada N., Nunez G., 2013. Role of the gut microbiota in the development and function of lymphoid cells. J. Immunol., 190, 1389-1395.

Khachatryan Z.A., Ktsoyan Z.A., Manukyan G.P., Kelly D., Ghazaryan K.A., Aminov R.I., 2008. Predominant role of host genetics in controlling the composition of gut microbiota. PLoS One. 26, e3064.

Khafipour E., Li S., Plaizier J.C., Krause D.O., 2009. Rumen microbiome composition determined using two nutritional models of subacute ruminal acidosis. Appl. Environ. Microbiol. 75, 7115-7124

Lanning D.K., Rhee K.J., Knight K.L., 2005. Intestinal bacteria and development of the B-lymphocyte repertoire. Trends Immunol., 26, 419-425.

Le Gall M., Gallois M., Seve B., Louveau I., Holst J.J., Oswald I.P., Lalles J.P., Guilloteau P., 2009. Comparative effect of orally administered sodium butyrate before or after weaning on growth and several indices of gastrointestinal biology of piglets. Br. J. Nutr., 102, 12851296.

Li R.W., Rinaldi M., Capuco A.V., 2011. Characterization of the abomasal transcriptome for mechanisms of resistance to gastrointestinal nematodes in cattle. Vet. Res., 42, 114.

Li R.W., Wu S., Li W., Navarro K., Couch R.D., Hill D., Urban J.F., Jr., 2012. Alterations in the porcine colon microbiota induced by the gastrointestinal nematode Trichuris suis. Infect. Immun., 80, 2150-2157.

Lotrich F.E., El-Gabalawy H., Guenther L.C., Ware C.F., 2011. The role of inflammation in the pathophysiology of depression: different treatments and their effects. J. Rheumatol., Suppl, 88, 48-54.

Lu K., Abo R.P., Schlieper K.A., Graffam M.E., Levine S., Wishnok J.S., Swenberg J.A., Tannenbaum S.R., Fox J.G., 2014. Arsenic exposure perturbs the gut microbiome and its metabolic profile in mice: an integrated metagenomics and metabolomics analysis. Environ. Health Perspect., 122, 284-291. 
Mann E.R., Landy J.D., Bernardo D., Peake S.T., Hart A.L., Al-Hassi H.O., Knight S.C., 2013. Intestinal dendritic cells: their role in intestinal inflammation, manipulation by the gut microbiota and differences between mice and men. Immunol. Lett., 150, 30-40.

Martin C., Brossard L., Doreau M., 2006. Mécanismes d'apparition de l'acidose ruminale latente et conséquences physiopathologiques et zootechniques. INRA Prod. Anim., 19, 93-107.

Maslowski K.M., Mackay C.R., 2011. Diet, gut microbiota and immune responses. Nat. Immunol., 12, 5-9.

Michelland R.J., Monteils V., Zened A., Combes S., Cauquil L., Gidenne T., Hamelin J., Fortun-Lamothe L., 2009. Spatial and temporal variations of the bacterial community in the bovine digestive tract. J. Appl. Microbiol., $107,1642-1650$

Michelland R.J., Combes S., Monteils V., Cauquil L., Gidenne T., Fortun-Lamothe L., 2011. Rapid adaptation of the bacterial community in the growing rabbit caecum after a change in dietary fibre supply. Animal, 5, 1761-1768.

Michelland R.J., Combes S., Monteils V., Bayourthe C., Cauquil L., Enjalbert F., Julien C., Kimsé M., Troegeler-Meynadier A., Zened A., Gidenne T., Fortun-Lamothe L., 2012. Analyse comparée des écosystèmes digestifs du rumen de la vache et du caecum du lapin. INRA Prod. Anim., 25, 395-406.

Million M., Lagier J.C., Yahav D., Paul M., 2013. Gut bacterial microbiota and obesity. Clin. Microbiol. Infect., 19, 305-313.

Moeller A.H., Degnan P.H., Pusey A.E., Wilson M.L., Hahn B.H., Ochman H., 2012. Chimpanzees and humans harbour compositionally similar gut enterotypes. Nat. Commun., 3, 1179 .

Moeller A.H., Ochman H., 2013. Factors that drive variation among gut microbial communities. Gut Microbes, 4, 403-408.

Monteils V., Cauquil L., Combes S., Godon J.J., Gidenne T., 2008. Potential core species and satellite species in the bacterial community within the rabbit caecum. FEMS Microbiol. Ecol., 66, 620-629.

Morgavi D.P., Kelly W.J., Janssen P.H., Attwood G.T., 2013. Rumen microbial (meta)genomics and its application to ruminant production. Animal, 7, Suppl 1, 184-201.

Morowitz M.J., Denef V.J., Costello E.K., Thomas B.C., Poroyko V., Relman D.A., Banfield J.F., 2011. Strain-resolved community genomic analysis of gut microbial colonization in a premature infant. Proc. Natl Acad. Sci. USA, 108, 1128-1133.

Mulder I.E., Schmidt B., Stokes C.R., Lewis M., Bailey M., Aminov R.I., Prosser J.I., Gill B.P., Pluske J.R., Mayer C.D., Musk C.C., Kelly D., 2009. Environmentally-acquired bacteria influence microbial diversity and natural innate immune responses at gut surfaces. BMC Biol., 7, 79, doi:10.1186/1741-7007-7-79.

Mulder I.E., Schmidt B., Lewis M., Delday M., Stokes C.R., Bailey M., Aminov R.I., Gill B.P., Pluske J.R., Mayer C.D., Kelly D., 2011. Restricting microbial exposure in early life negates the immune benefits associated with gut colonization in environments of high microbial diversity. PLoS One, 6, e28279.

Oikonomou G., Teixeira A.G., Foditsch C., Bicalho M.L., Machado V.S., Bicalho R.C.,
2013. Fecal microbial diversity in pre-weaned dairy calves as described by pyrosequencing of metagenomic 16S rDNA. Associations of Faecalibacterium species with health and growth. PLoS One, 8, e63157.

Ottaviani E., Ventura N., Mandrioli M., Candela M., Franchini A., Franceschi C., 2011. Gut microbiota as a candidate for lifespan extension: an ecological/evolutionary perspective targeted on living organisms as metaorganisms. Biogerontology, 12, 599-609.

Phocas F., Bobe J., Bodin L., Charley B., Dourmad J.Y., Friggens N.C. Hocquette J.F., Le Bail P.Y., Le Bihan-Duvao E., Mormède P., Quéré P., Schelcher F., 2014., Des animaux plus robustes : un enjeu majeur pour le développement durable des productions animales nécessitant l'essor du phénotypage fin et à haut débit. In : Phénotypage des animaux d'élevage. Phocas F. (Ed). Dossier, INRA Prod. Anim., 27, 181-194.

Pluske J.R., 2013. Feed- and feed additivesrelated aspects of gut health and development in weanling pigs. J. Anim. Sci. Biotechnol., 4, 1.

Qin J., Li R., Raes J., Arumugam M., Burgdorf K.S., Manichanh C., Nielsen T., Pons N., Levenez F., Yamada T., Mende D.R., Li J., Xu J., Li S., Li D., Cao J., Wang B., Liang H., Zheng H., Xie Y., Tap J., Lepage P., Bertalan M., Batto J.M., Hansen T., Le Paslier D., Linneberg A., Nielsen H.B., Pelletier E., Renault P., Sicheritz-Ponten T., Turner K., Zhu H., Yu C., Jian M., Zhou Y., Li Y., Zhang X., Qin N., Yang H., Wang J., Brunak S., Doré J., Guarner F., Kristiansen K., Pedersen O., Parkhill J., Weissenbach J., Bork P., Ehrlich S.D., 2010. A human gut microbial gene catalogue established by metagenomic sequencing. Nature, 464, 59-65.

Rist V.T., Eklund M., Bauer E., Sauer N., Mosenthin R., 2012. Effect of feeding level on the composition of the intestinal microbiota in weaned piglets. J. Anim. Sci., 90, Suppl 4, 19-21.

Rosenstiel P., 2013. Stories of love and hate: innate immunity and host-microbe crosstalk in the intestine. Curr. Opin. Gastroenterol., $29,125-132$.

Salonen A., de Vos W.M., Palva A., 2010 Gastrointestinal microbiota in irritable bowel syndrome: present state and perspectives. Microbiology, 156, 3205-3215.

Sansonetti P.J., 2011. To be or not to be a pathogen: that is the mucosally relevant question. Mucosal. Immunol., 4, 8-14.

Sayegh C.E., Ratcliffe M.J., 2000. Perinatal deletion of B cells expressing surface Ig molecules that lack V(D)J-encoded determinants in the bursa of Fabricius is not due to intrafollicular competition. J. Immunol., 164, 5041-5048.

Schmidt B., Mulder I.E., Musk C.C., Aminov R.I., Lewis M., Stokes C.R., Bailey M., Prosser J.I., Gill B.P., Pluske J.R., Kelly D., 2011. Establishment of normal gut microbiota is compromised under excessive hygiene conditions. PLoS One, 6, e28284.

Segata N., Haake S.K., Mannon P., Lemon K.P., Waldron L., Gevers D., Huttenhower C., Izard J., 2012. Composition of the adult digestive tract bacterial microbiome based on seven mouth surfaces, tonsils, throat and stool samples. Genome Biol., 13, R42.

Sekelja M., Rud I., Knutsen S.H., Denstadli V., Westereng B., Naes T., Rudi K., 2012. Abrupt temporal fluctuations in the chicken fecal microbiota are explained by its gastrointestinal origin. Appl. Environ. Microbiol., 78, 29412948.
Shirkey T.W., Siggers R.H., Goldade B.G., Marshall J.K., Drew M.D., Laarveld B., Van Kessel A.G., 2006. Effects of commensal bacteria on intestinal morphology and expression of proinflammatory cytokines in the gnotobiotic pig. Exp. Biol. Med., 231, 1333-1345.

Shojadoost B., Vince A.R., Prescott J.F., 2012. The successful experimental induction of necrotic enteritis in chickens by Clostridium perfringens: a critical review. Vet. Res., 43, 74.

Sommer F., Backhed F., 2013. The gut microbiota-masters of host development and physiology. Nat. Rev. Microbiol., 11, 227-238.

Sonnenberg G.F., Fouser L.A., Artis D., 2011. Border patrol: regulation of immunity, inflammation and tissue homeostasis at barrier surfaces by IL-22. Nat. Immunol., 12, 383-390.

Spor A., Koren O., Ley R., 2011. Unravelling the effects of the environment and host genotype on the gut microbiome. Nat. Rev. Microbiol., 9, 279-290.

Suzuki K., Ha S.A., Tsuji M., Fagarasan S., 2007. Intestinal IgA synthesis: a primitive form of adaptive immunity that regulates microbial communities in the gut. Semin. Immunol., 19, 127-135.

Taschuk R., Griebel P.J., 2012. Commensal microbiome effects on mucosal immune system development in the ruminant gastrointestinal tract. Anim. Health Res. Rev., 13, 129141.

Torok V.A., Ophel-Keller K., Loo M., Hughes R.J., 2008. Application of methods for identifying broiler chicken gut bacterial species linked with increased energy metabolism. Appl. Environ. Microbiol., 74, 783-791.

Turnbaugh P.J., Hamady M., Yatsunenko T., Cantarel B.L., Duncan A., Ley R.E., Sogin M.L., Jones W.J., Roe B.A., Affourtit J.P., Egholm M., Henrissat B., Heath A.C., Knight R., Gordon J.I., 2009. A core gut microbiome in obese and lean twins. Nature, 457, 480-484.

Vrieze A., de Groot P.F., Kootte R.S., Knaapen M., van Nood E., Nieuwdorp M., 2013. Fecal transplant: A safe and sustainable clinical therapy for restoring intestinal microbial balance in human disease? Best Pract. Res. Clin. Gastroenterol., 27, 127-137.

Willing B.P., Van Kessel A.G., 2007. Enterocyte proliferation and apoptosis in the caudal small intestine is influenced by the composition of colonizing commensal bacteria in the neonatal gnotobiotic pig. J. Anim. Sci., 85, 3256-3266.

Willing B.P., Van Kessel A.G., 2009. Intestinal microbiota differentially affect brush border enzyme activity and gene expression in the neonatal gnotobiotic pig. J. Anim. Physiol. Anim. Nutr., 93, 586-595.

Wong S., Rawls J.F., 2012. Intestinal microbiota composition in fishes is influenced by host ecology and environment. Mol. Ecol., 21, 3100-3102.

Xu Z., Parra D., Gomez D., Salinas I., Zhang Y.A., von Gersdorff Jorgensen L., Heinecke R.D., Buchmann K., Lapatra S., Sunyer J.O., 2013. Teleost skin, an ancient mucosal surface that elicits gut-like immune responses. Proc. Natl. Acad. Sci. USA., 110, 13097-13102.

Yeoman C.J., Chia N., Jeraldo P., Sipos M., Goldenfeld N.D., White B.A., 2012. The microbiome of the chicken gastrointestinal tract. Anim. Health Res. Rev., 13, 89-99. 
Yi P., Li L., 2012. The germfree murine animal: an important animal model for research on the relationship between gut microbiota and the host. Vet. Microbiol., 157, 1-7.
Zebeli Q., Metzler-Zebeli B.U., 2012. Interplay between rumen digestive disorders and dietinduced inflammation in dairy cattle. Res. Vet. Sci., 93, 1099-1108.
Zhu X.Y., Zhong T., Pandya Y., Joerger R.D., 2002. 16S rRNA-based analysis of microbiota from the cecum of broiler chickens. Appl. Environ. Microbiol., 68, 124-137.

\section{Résumé}

Le microbiote digestif est un symbionte dont on a démontré l'implication essentielle dans la régulation de la physiologie de l'hôte qui l'héberge pour la digestion, le métabolisme et l'immunité. Ce microbiote a en particulier un rôle majeur, et jusqu'ici sous-estimé, sur la santé de son hôte et participe à son adaptabilité à des environnements changeants. Les technologies de séquençage à haut débit devraient faciliter l'inclusion de cet écosystème complexe dans le phénotypage des animaux d'élevage. Il faut pour ce faire prendre en compte sa composition, sa diversité, sa stabilité au cours du temps et ses variations selon différents facteurs comme le génotype de l'hôte, l'alimentation et les conditions d'élevage. Ces connaissances devraient permettre de définir les propriétés d'un microbiote digestif «normal » associé à une bonne santé, d'en préciser les dysfonctionnements et de comprendre leurs répercussions sur l'état de santé de l'animal. Cela conduira à identifier des marqueurs de diagnostic et de pronostic de ces dysfonctionnements, fournissant des moyens de contrôle nouveaux de la santé en élevage, appréhendée en terme d'optimisation des rendements de production, de résistance aux maladies et de maintien du bien-être. A terme, le contrôle du microbiote digestif par l'alimentation, la génétique ou les pratiques d'élevage permettra de favoriser l'adaptation des animaux à leur environnement d'élevage en améliorant leur robustesse, de limiter l'utilisation d'antibiotiques et de préserver la sécurité sanitaire des aliments en évitant le développement de bactéries pathogènes pour l'Homme. L'ampleur des données à générer et à analyser pour les différentes espèces d'intérêt reste le défi à relever.

\section{Abstract}

Integrating the characterization of digestive microbiota in phenotyping livestock animals: towards a new tool for animal health control?

The gastrointestinal microbiota is a symbiont deeply involved in the physiology of its host through the regulation of digestion, metabolism and immunity and consequently in the host adaptability to changing environments. In particular, the role of the gastrointestinal microbiota in maintaining host health is important and has been under-estimated until now. It is an inherent component of the animal that should be described when phenotyping animals. The rapid development of high throughput sequencing technologies facilitates the description of this complex ecosystem in livestock species. For each animal species, its description should include the measure of its composition, diversity and stability over time and the measure of its variability according to different factors such as genotype, nutrition and breeding conditions. This knowledge should allow defining the properties of a 'normal' gastrointestinal microbiota associated with health, identifying the microbiota dysfunctions and understanding their consequences on host physiology. It will lead to the identification of diagnostic and prognostic markers for gastrointestinal dysbiosis thus furnishing new tools for promoting health. Finally, the manipulation of the gastrointestinal microbiota will constitute a way to better adapt animals to their environment by improving their robustness, limit the use of antibiotics and improve food safety by preventing the development of bacteria threatening human health. Due to the high quantity of data to be acquired and analyzed, achieving these objectives for each species of interest remains a challenge.

CALENGE F., MARTIN C., LE FLOCH N., PHOCAS F., MORGAVI D., ROGEL-GAILLARD C., QUÉRÉ P., 2014. Intégrer la caractérisation du microbiote digestif dans le phénotypage de l'animal de rente : vers un nouvel outil de maîtrise de la santé en élevage ? In : Phénotypage des animaux d'élevage. Phocas F. (Ed). Dossier, INRA Prod. Anim., 27, $209-222$. 